Illinois State University

ISU ReD: Research and eData

Theses and Dissertations

9-26-2013

\title{
The Ethos of Excellence in an Effective School: A Study of an Exemplary Urban School
}

Karen Danita Gyenfie

Illinois State University, ladykdg@aol.com

Follow this and additional works at: https://ir.library.illinoisstate.edu/etd

Part of the Elementary and Middle and Secondary Education Administration Commons, and the Elementary Education and Teaching Commons

\section{Recommended Citation}

Gyenfie, Karen Danita, "The Ethos of Excellence in an Effective School: A Study of an Exemplary Urban School" (2013). Theses and Dissertations. 21.

https://ir.library.illinoisstate.edu/etd/21

This Dissertation is brought to you for free and open access by ISU ReD: Research and eData. It has been accepted for inclusion in Theses and Dissertations by an authorized administrator of ISU ReD: Research and eData. For more information, please contact ISUReD@ilstu.edu. 


\title{
THE ETHOS OF EXCELLENCE IN AN EFFECTIVE SCHOOL: A STUDY OF AN EXEMPLARY URBAN SCHOOL
}

\author{
KAREN D. GYENFIE
}

\author{
A Dissertation Submitted in \\ Partial Fulfillment of the Requirements \\ for the Degree of \\ DOCTOR OF EDUCATION \\ Department of Educational Administration and Foundations \\ ILLINOIS STATE UNIVERSITY
}


THE ETHOS OF EXCELLENCE IN AN EFFECTIVE SCHOOL: A STUDY OF AN EXEMPLARY URBAN SCHOOL

KAREN D. GYENFIE

DISSERTATION APPROVED:

\begin{tabular}{ll}
\hline Date & Paul Baker, Chair \\
\hline Date & Albert Azinger \\
& \\
\hline Date & Joseph Pacha \\
\hline Date & Neil Sappington
\end{tabular}




\title{
THE ETHOS OF EXCELLENCE IN AN EFFECTIVE SCHOOL:
}

\section{A STUDY OF AN EXEMPLARY URBAN SCHOOL}

\author{
Karen D. Gyenfie
}

145 Pages

December 2009

This research project was organized in three phases. Phase I began with the selection of the high performing urban school site to be studied. Phase II of the study centered on the researcher's study of the school's policies, curriculum, instructional practices, personnel, and related artifacts. This involved school site observations, group and individual interviews, and surveys. Phase III of the study involved a detailed analysis of interview and survey data, field notes, and artifacts. The researcher processed, analyzed, and coded all data in accordance to qualitative standards in order to identify those indigenous practices that impact the success of the school.

The findings of the study included the following:

1. School improvement is a multifaceted endeavor that requires the commitment of the entire school community.

2. Schools seeking to improve must strengthen multiple areas such as those identified in the NCEA Best Practice Framework (curriculum and academic goals; staff selection, leadership and capacity building; instructional programs, practices, and arrangements; monitoring, compilation, analysis and use of data; recognition, intervention and adjustment). 
3. Schools must develop relational trust, maintain instructional program coherence, and establish a professional learning community to realize sustained improvements that will result in increased student achievement.

4. Finally, none of these laudable precepts identified by best practices, relational trust, and instructional program coherence would have any chance without a highly competent principal who embodies respect for the school's students, teachers, and parents. 


\section{ACKNOWLEDGMENTS}

I offer my deepest appreciation to my committee members, Dr. Neil Sappington, Dr. Joseph Pacha, Dr. Albert Azinger, and Dr. Paul Baker, for their guidance and support. To Dr. Paul Baker, my committee chair, I am forever grateful for your patience, unwavering support and perseverance throughout this project and my life's challenges. I will never forget all the times you called to get me back on track. You truly kept my eye on the prize. It has been an honor and pleasure working with you and learning from you.

To my parents, Oliver W. and Naomi Norris, who called often to make sure I was working on my dissertation and threatened me with a visit to the wood shed, I am so proud that I have finished thanks to your loving encouragement and financial support. To my husband Sam Gyenfie thanks for loving me through it all. To my daughter Ekua Gyenfie, I hope my journey will inspire you someday. To my grandchildren Khalid and Khalani, thanks for your love and patience, now we can do some fun things together. To my sisters Donna Norris and Sharon Russell, I am thankful for your love and support. To my brother Vincent Norris (the family grill master), I am forever grateful for your loving encouragement and support. To my brother Daryl Norris, my cousin Pat Norris-Williams and her husband Bill, who called on me often to check the progress of "our dissertation," I am happy to report that "our dissertation" is complete. To my brother, Mark Norris, who repeatedly offered to write a chapter on his perspective in my dissertation, I appreciate your offer but no thanks. To all my family, friends and loved ones who have 
encouraged, and supported me through this project, I am truly blessed to have such wonderful people as my family and friends.

To Pat McCarney, you were a fabulous help with the editing and formatting my work on this document. I thank you for all your services, understanding and support.

Finally, I thank God for giving me the strength and perseverance to complete this project. There were many times that prayer gave me a renewed perspective that enabled me to continue on through so many hardships that invaded my life during this project. To God be the glory.

K. D. G. 


\section{CONTENTS}

Page

ACKNOWLEDGMENTS $\quad$ i

CONTENTS

TABLES vii

CHAPTER

I. THE PROBLEM STATEMENT AND ITS COMPONENTS 1

What is School Effectiveness? 4

What are the Characteristics of School Effectiveness?

Effective Schools Models $\quad 6$

Professional Learning Community $\quad 11$

Relational Trust $\quad 11$

Instructional Program Coherence $\quad 14$

Statement of the Problem $\quad 15$

Definition of Terms $\quad 16$

Research Questions 17

Design of the Study 17

Significance of the Study $\quad 19$

Assumptions $\quad 19$

Delimitations $\quad 19$

$\begin{array}{ll}\text { Organization of the Study } & 20\end{array}$

II. REVIEW OF RELATED LITERATURE 21

$\begin{array}{ll}\text { School Effectiveness Movement Beginning } & 21\end{array}$

Federal Involvement Begins $\quad 21$

Search for Effective Schools 22

Implementing Effective School Principles $\quad 25$

$\begin{array}{ll}\text { Curriculum and Academic Goals } & 26\end{array}$

$\begin{array}{ll}\text { Implementation Challenges } & 27\end{array}$

Staff Selection, Leadership and Capacity Building 28 
Staff Selection $\quad 28$

Leadership $\quad 29$

Capacity Building $\quad 30$

Instructional Programs, Practices, and Arrangements 32

Instructional Programs $\quad 32$

Practices and Arrangements $\quad 33$

Monitoring: Compilation, Analysis, and Use of Data 34

Recognition, Intervention, and Adjustments 35

Recognition $\quad 35$

Intervention and Adjustments $\quad 36$

Relational Trust $\quad 37$

Instructional Program Coherence $\quad 40$

Principal Leadership $\quad 42$

Professional Learning Community $\quad 47$

$\begin{array}{ll}\text { III. METHODOLOGY } & 52\end{array}$

Statement of the Problem $\quad 52$

Background of the Study $\quad 52$

Research Questions $\quad 53$

Research Design $\quad 54$

Phase I $\quad 55$

Site Selection $\quad 55$

Phase II $\quad 56$

Description of the Sample $\quad 59$

Protection of Human Subjects $\quad 59$

Analysis of Data $\quad 60$

$\begin{array}{ll}\text { Phase III } & 60\end{array}$

$\begin{array}{ll}\text { Summary } & 61\end{array}$

IV. RESULTS 63

School Profile 64

Research Question Findings $\quad 67$

$\begin{array}{ll}\text { Research Question } 1 & 67\end{array}$ 
Theme 1: Curriculum and academic goals

Theme 2: Staff selection, leadership, and capacity building

Theme 3: Instructional programs, practices, and arrangements

Theme 4: Monitoring, compilation, analysis, and use of data

Theme 5: Recognition, intervention, and adjustment

Research Question 2

Research Question 3

Prevailing condition 1

Prevailing condition 2

96

Prevailing condition 3

Research Question 4

Instructional leadership

Motivational leadership

Research Question 5

104

Summary: An Emerging Professional Learning Community 108

V. CONCLUSIONS, IMPLICATIONS, AND RECOMMENDATIONS

Overview of the Study

Statement of the Problem

Design of the Study

Description of the School

Summary of Findings and Conclusions

Theme 1: Curriculum and academic goals

Theme 2: Staff selection, leadership, and capacity building

Theme 3: Instructional programs, practices, and arrangements

Theme 4: Monitoring, compilation, analysis, and use of data 
Research Question 2

Research Question 3

117

Research Question 4

118

Research Question 5

Implications and Recommendations for Policy and Practice

122

Implications

122

Considerations for Further Research

125

Recommendations for Policy and Practice

126

Conclusion

127

REFERENCES 129

APPENDIX A: NCEA Interview Protocol for Teachers and Administrators

133

APPENDIX B: NCEA/Illinois Best Practice Framework

138

APPENDIX C: Letter of Explanation and Consent to Participate

140

APPENDIX D: Relational Trust Survey Protocol

143 


\section{TABLES}

Table Page

1. Teacher-Principal Relations $\quad 89$

2. Teacher-Teacher Role Relations 90

3. Teacher-Parent Role Relations 91

4. Interconnections: NCEA Themes, Professional Learning Community (PLC), Instruction Program Coherence (IPC) Relational Trust (RT) 


\section{CHAPTER I}

\section{THE PROBLEM STATEMENT AND ITS COMPONENTS}

Since its beginning in the $19^{\text {th }}$ century, American public education has been a focus of change, idealism, and struggle. As society evolved, the agenda for public education expanded further as a compulsory system that would solve social ills as well as produce good citizens and workers. Through the $20^{\text {th }}$ century, education has changed to reflect the ideas and societal needs of each particular era. Curriculum and pedagogy have evolved from a very basic focus to that of a highly trained technological focus. Today's global society demands citizens who are adept in academic disciplines as well as critical thinkers.

Four main problems plague urban education today. These problems are low student achievement, violence in schools, student disengagement, and high dropout rates (Wasley, 2000). However, across the nation political and business leaders most often criticize educators citing low student achievement resulting in an inability of students to compete globally. "A clear pattern has emerged from years of polling: the public is much more concerned about schools across the nation than they are about schools in their own neighborhood"' (Baker, 1999, p. 158). In fact, a highly publicized report commissioned by the United States Government concluded:

Our once unchallenged preeminence in commerce, industry, science, and technological innovations is being overtaken by competitors throughout the world. Our society and its education institutions seem to have lost sight of the 
basic purpose of schooling and the high expectations and disciplined efforts needed to attain them. (A Nation at Risk, 1983)

Since this scathing report, other publicized criticisms of public education have followed.

Key players in the authority structures and advocacy groups place professional educators (state superintendents to teachers) and lay officials (board members) in the middle. No one is in charge in this unwieldy world; and everyone can blame at least two other parties alongside, above, and below them in the authority system for obstructing needed changes that would yield meaningful improvement. In short, it is a challenging time for educational leaders. (Baker, 1999, p. 154)

As a result, public education has sustained many changes ranging from how educators are trained, class size reduction, and increased spending per pupil to standardized curriculums and mandatory minimum scores for individual student promotions. Nevertheless, student achievement remains low and continues to lag behind the educational standards set by state officials. In fact, declining student achievement among the urban poor has been a very controversial issue in educational debates dating back to the 1960 s and remains so today. Moreover, the widening gap in student achievement between urban versus the suburban areas and even more disturbing is the gap between high and low socioeconomic groups. The problem plainly stated is that students from poor families consistently trail the academic achievement of economically affluent students.

Currently, politicians build their campaign speeches on the ills of the public education system and most often cite declining student achievement. In 2001, President George W. Bush signed into legislation the "No Child Left Behind Act" (NCLB). The NCLB legislation has changed public education for teachers and school administrators; it has also increased the federal government's seemingly dormant involvement in education. 
The "No Child Left Behind Act" substantially increases the testing requirements for states and sets demanding accountability standards for schools, districts, and states with measurable adequate yearly progress (AYP) objectives for all students and subgroups of students defined by socioeconomic background, race-ethnicity, English language proficiency, and disability. (Linn et al., 2002)

The NCLB Act calls for all students at or above the proficient level within 12 years-by the year 2014.

The implications of the NCLB act for teachers and school administrators are rather serious, since the lofty goals of this law seem impossible for many schools to achieve. The "No Child Left Behind" law establishes average yearly progress goals for schools to meet for all students in a wide array of categories: poverty, race, gender, English as a Second Language, and special education. Schools that fail to meet AYP for 2 consecutive years face a series of interventions that eventually lead to loss of funding, closing the school, or a takeover by external administrators. In each state the State Board of Education has been charged with the responsibility of developing curricular standards and standardized testing to measure the mastery of the state standards. States must also implement the provisions of NCLB and monitor AYP.

The Illinois State Board of Education (ISBE) had an education plan for improving schools prior to NCLB, which included a set of curricular standards for all grades and standardized testing in reading, mathematics, and writing for grade levels 3, 5, and 7. NCLB mandates have modified this system with requirements to test grade levels 3 through 8. The ISBE plan also had sanctions for failing schools and rewards for schools that meet proficiency levels prior to NCLB. The ISBE plan put poor performing schools on either an "Academic Watch List" or an "Academic Warning List"; both lists involve sanctions. Schools meeting high proficiency levels as defined by ISBE could receive 
rewards, including public recognition (praise) and monetary rewards. Schools failing to meet minimum proficiency levels as defined by ISBE could also face a less favorable public recognition (ridicule) or external intervention. The most serious sanction usually implemented after several years of school failure is the dissolution or closure of the school. Despite the Illinois State Board of Education's efforts to improve student achievement, student achievement remains low for many schools across the state, especially in urban areas. With the urgent demands for school improvement across the nation, it is important to examine what constitutes school effectiveness.

\section{What is School Effectiveness?}

There is no common definition of school effectiveness, and many groups may have different perceptions of it (Stoll \& Fink, 1996). Many people have a very simplistic perception of school effectiveness that only considers standardized test data and national averages. The problem created by this simplistic perception is that student progress is ignored. Student progress is the actual gains made by each student in a particular school year. Student progress is determined by the difference between the academic mastery level students begin the school year with versus the academic mastery level attained by the end. Therefore, it certainly makes sense that school effectiveness should be interpreted in terms of student achievement and gains. Stoll and Fink (1996) quoted Mortimore (1991) to define "an effective school is one in which pupils progress further than might be expected from consideration of its intake" (p. 27). Stoll and Fink also noted that "at school level, all those concerned need to come to shared definition and agreement on expected and desirable outcomes" (p. 27). 


\section{What are the Characteristics of School Effectiveness?}

In reaction to the problems that many schools were facing in the education of poor urban children and the scathing criticisms, a group of educational researchers (George Weber, Wilbur Brookover, and Ronald Edmonds) began to study the phenomenon. They discovered schools that were instructionally effective in educating poor urban students and making a difference in their lives. In a 1971 study, Weber found four inner city schools in which reading achievement was clearly successful for poor children on the basis of national norms (Edmonds 1979). These researchers studied the practices of the successful school and identified characteristics that were common to successful schools. From that study, some common characteristics were identified. All four schools had strong leadership, "high expectations for all students, an orderly climate, and a strong emphasis on pupil acquisition of reading skills" (Edmonds 1979). These earlier findings sparked the interest of an educational researcher, Ronald Edmonds (1979), who believed that "Inequity in American education derives first and foremost from our failure to educate the children of the poor." Edmonds (1979) contended that "There has never been a time in the life of the American public school when we have not known all we needed to in order to teach all those whom we choose to teach." Building on the research of Weber and his own work, Edmonds (1979) confirmed, "Urban schools that teach poor children successfully have strong leadership and a climate of expectation that students will learn." This research lead the way to many studies of effective schools and has resulted in many models. 


\section{Effective Schools Models}

Out of Edmond's research into improving education for the nation's poor children grew the "Effective Schools Research" model. The major tenants of the Effective Schools Research, Edmonds (1979) noted, were "the most tangible and indispensable characteristics of effective schools." The characteristics of this model are as follows:

1. They have strong administrative leadership without which the disparate elements of good schooling can neither be brought together nor kept together.

2. Schools that are instructionally effective for poor children have a climate of expectation in which no children are permitted to fall below minimum but efficacious levels of achievement.

3. The schools atmosphere is orderly without being rigid, quiet without being oppressive, and generally conducive to the instructional business at hand.

4. Effective schools get that way partly by making it clear that pupil acquisition of basic skills takes precedence over all other school activities.

5. When necessary, school energy and resources can be diverted from other business in furtherance of the fundamental objectives.

6. There must be some means by which pupil progress can be frequently monitored. The principal and teachers remain constantly aware of pupil progress in relationship to instructional objectives. (Edmonds 1979)

These characteristics of effective schools later became known as Edmonds' "Correlates of Effective Schools." "The body of research and practices commonly called "Effective Schools" has been a significant force in education reform during the past two decadesperhaps the most significant force for improving teaching and learning for disadvantaged and minority children" (Becker, Myron, et al., 1992). These Effective School Correlates are widely used today by schools in school improvement planning frameworks and adopted by state agencies such as the ISBE. The Effective School Correlates appear logical and make School Improvement Plans look effective, but, in fact, many schools have not realized successful implementation and sustainability. While the Effective Schools process for school improvement was widely promoted and many programs were 
introduced in thousands of schools throughout the nation, the problem of low achievement among poor urban students continued to exist and draw public attention.

Another more current body of educational research conducted by the National Center for Educational Accountability (NCEA) called the "Best Practice Framework" provides an effective school formula that corresponds to earlier findings by Edmonds. Like the previous work on effective schools correlates, the "Best Practice Framework" is intended to help low performing schools improve. Luce (2005) believes that "One outgrowth of the increased attention on evidence-based reform has been a profusion of "best practice studies,' which generally focus on locating high-performing schools, determining what they are doing to drive student achievement, and sharing those practices with others" (p. 60). Somewhat similar to the Edmonds Effective Schools Correlates, NCEA has identified five central themes around which high-performing schools and districts focus their instructional practices. The "five central themes" of this model are:

1. Curriculum and Academic Goals: Practices in this theme enable highperforming school systems to establish clear, specific academic goals that apply to all students in every grade of their education. All educators agree upon these learning goals and are held accountable for enabling each child to reach them.

2. Staff Selection, Leadership, and Capacity Building: These practices facilitate the selection and development of high-quality teachers and instructional leaders, including district leadership, school principals, and teachers.

3. Instructional Programs, Practices and Arrangements: Practices concern the provision of tools - such as instructional materials, adequate instructional time, and technology.

4. Monitoring: Compilation, Analysis, and Use of Data: Practices employ student performance data to determine how students are performing, to pinpoint each student's academic strengths and weaknesses, and to know what instructional techniques and materials are effective.

5. Recognition, Intervention, and Adjustment: The practices concern how educators in high-performing schools and districts use the information from student performance data to recognize the academic needs of each student and provide 
immediate and intense intervention to attend to those needs. (Luce, 2005, pp. 67-68)

Each of the five above-mentioned themes has interrelated practices at three levels: district, school, and classroom. Each level has its specific practices to be performed and together creates the Best Practice Framework, which is proclaimed to be common practices in high-performing schools.

Theme one addresses curriculum and academic goals. The district level is responsible for establishing clear objectives for every grade level. Guidelines for this task have been set by the State Board of Education as required by the federal No Child Left Behind mandates. At the school level, the objectives for each grade level should be reflected in the school's plan for improvement. At the classroom level, instruction should reflect content based on the specific objectives. Although this theme may seem very "cut and dried" at the classroom level, it is most difficult. Providing specific content based on specific objectives requires extensive time, preparation, and sources. This task is best completed by a grade level team and honed over time and practice. Preparation time and collaboration are luxuries not always afforded teachers in many schools. The limited hours in any given day do not accommodate the many tasks a teacher is held accountable for performing.

Theme two is a complex set of factors that result in school effectiveness. This theme involves leadership, capacity building, and staff selection. Leadership sets the tone for all interactions that must take place in an institution. Leadership creates opportunities for preparation time, teamwork, staff collaboration, and development. Leadership includes teachers who participate in ideas and projects regarding curriculum and 
instructional program issues. All too often these decisions are made for the teachers without regard to their real needs. At the district level, administrators must provide policies and procedures, and the selection of strong highly qualified leaders and teachers. The school level must assist in the selection of highly qualified teachers and organize the school based on student learning needs. At the classroom level, teachers must collaborate on grade level teams that focus on content, instruction, assessment, and student work.

Theme three addresses the instructional program, practices, and arrangements. The district level provides evidence-based instructional programs that have an established record of successful outcomes. District leaders must scrutinize instructional programs according to curriculums that assure effectiveness. The school level ensures the use of these instructional programs and materials. The classroom level is charged with the actual use of these programs, materials, and adherence to the arrangements. Teachers should be included in the selection of instructional programs and materials because they will ultimately be the users of these.

The emphasis in theme four is monitoring student data and data-driven decision making. The district level develops and monitors assessment data along with overall school performance. The school level monitors teacher performance and student learning. Teachers monitor student learning at the classroom level. Luce and Thompson (2005) contend, "The first and fundamental step to improving our education system is employing student performance information to determine our students' achievement levels as well as what effective programs should be put into place to optimize students' academic performance" (p. 26). Edmonds (1979) also included monitoring student progress in his Effective School Correlates. Luce and Thompson go on to suggest that 
data-driven decision making substantiates results, and most educators would concur. In fact, since the innovations of scientific management in the progressive era, educators have been using student data to place students in groups, promote or retain students, and report student progress.

Theme five addresses recognition of success, intervention for areas of weakness, and adjustments to support special needs. This theme involves celebrating successes and responding to areas of concern before failure rears its head. Recognition and celebration of successes is a valuable practice that motivates people to strive harder. The district level recognizes successes and is also involved in intervention or adjustment measures based on school performance. Likewise, the school level also recognizes and celebrates successful teacher and student performance. The school level is directly charged with intervention or adjustment based on teacher and student performance. In the classroom, teachers recognize and celebrate student successes as well as intervene for those students who need extra help.

The information presented in Luce's (2005) five themes is not new groundbreaking news to educators, and much of it resembles the earlier research done by Edmonds and other researchers of effective schools. Other school reformers and researchers have approached the topic of school effectiveness with additional concepts and images of a successful school. In this study, special attention is given to these promising areas of inquiry: professional learning community, instructional program coherence, and relational trust. 


\section{Professional Learning Community}

A professional learning community is an organizational arrangement in a school where teachers and administrators establish collegial relationships to continuously seek and share learning and then act on what they learn in order to improve their effectiveness as professionals and improve the teaching and learning process for students. "Learning communities are found in classrooms and schools where everyone (students, teachers, administrators, parents) is a teacher and a learner" (Baker, 1990). Baker (1996) quotes Senge (1990) in suggesting "part of the meaning of membership in a learning community is the willingness of all participants (regardless of formal titles) to see themselves as learners who are open to inquiry."

In a professional learning community, the school leader shares school leadership by inviting staff input in decision making especially involving the instructional framework. There is also collective research and learning among staff, which is used to address students' needs. Research literature has shown that effective professional learning communities also have a shared vision that is developed from the staff's commitment to students' learning. Effective professional learning communities provide coaching, support, assistance, and feedback for teachers to ensure continuous improvement. Relational trust and instructional program coherence are integral aspects of a professional learning community and are believed to be the unique characteristics that contribute to a school's success.

\section{Relational Trust}

Relational trust is a factor that greatly impacts the success of any organization. Thus, the dynamics of trust cannot be underestimated in the school setting among all key 
players, starting first and foremost with the leader. It is important to emphasize again that the leader sets the tone in the school. Trust undergirds all collegial interactions in any workplace, school, or even family. In fact, relational trust directly impacts school culture. Bryk (2002, p. 14) defines relational trust as an "organizational property in that its constitutive elements are socially defined in the reciprocal exchanges among participants in a school community." Relational trust involves interpersonal exchanges organized around a set of role relationships among the key players in a school: teachers with students, teachers with others teachers, teachers with parents, and teachers with the school principal (Bryk, 2002). Each participant must fulfill obligations and hold expectations regarding the obligations of other key players in the school. Foremost, teachers must interact with students. Teachers must gain the respect and cooperation of children in order to teach them. Teachers must hold high academic expectations for children and provide opportunities through instruction and intervention for them to succeed. Children expect teachers to teach them, to care about them, to treat them fairly and to address their needs with dignity. Teachers must interact with other teachers to develop and implement curriculum, instructional strategies, student assessments, and student support programs. Likewise, teachers expect support from administration, parents and from each other. Teachers expect that other teachers along the vertical grade level continuum will cover the prescribed curriculum for that grade level so that students will enter the next grade with the basic prerequisite skills in order to begin instruction at the next level. Teachers must interact with parents in order to gain their support in the education of the children. Teachers expect parents to have children at school on time every day, monitor children's behavior and homework, and have the required supplies to do their work. Parents expect 
teachers to respect them for who they are, overlooking their individual circumstances.

Parents expect their children to be taught by highly qualified professionals who will treat children fairly and nurture them with dignity. Teachers must also interact with the school principal. Teachers expect principals to support them in the classroom and provide funding for instructional and curricular materials, and meaningful professional development and make opportunities through scheduling for teachers to work together. Teachers expect principals to be honest, fair, ethical and work hard to facilitate school improvement efforts. Likewise, principals expect teachers to maintain a professional conduct, to be punctual with good attendance, work hard at teaching students, and work cooperatively with other teachers in the implementation curricular and instructional goals.

Participants bring several lenses to bear as they observe and interpret the behavior of others in school settings. We posit a dynamic interplay among four considerations: respect, competence, personal regard for others and integrity. Individual school community members simultaneously analyze the behavior of others through all four lenses. A serious deficiency on any one criterion can be sufficient to undermine a discernment of trust for the overall relationship. (Bryk 2002, pp. 22-23)

In schools, teachers must hold a certain degree of respect for the leader, parents, students and each other. Without this level of mutual respect, interactions could become adversarial. Likewise, the staff must believe in the competence of the leader to move the school toward progress and in each other's competence and stand ready to help strengthen each other in areas of weakness. There must be a high degree of personal regard of others and the success of the organization. One must genuinely care about how his/her actions impact others. "Trust deepens as individuals perceive that others care about them" (Bryk, 2002). The extreme importance of integrity to any workplace cannot be ignored. "In our daily social encounters, we listen to what people say and watch what 
they do. We think of individuals as having integrity if there is consistency between what they say and do" (Bryk, 2002). When people lack integrity, any level of trust others may have had is destroyed. When leaders lack integrity their credibility is destroyed and this greatly diminishes leadership capabilities.

All dimensions of relational trust are important in organizing a school into a functioning professional learning community, and all other factors that contribute to high quality performance. With a professional learning community firmly in place, the key players in a school can begin the most important work of building instructional program coherence.

\section{Instructional Program Coherence}

"Instructional program coherence is a set of interrelated programs for students and staff that are guided by a common framework for curriculum, instruction, assessment, and learning climate and that are pursued over a sustained period" (Newmann, Smith, Allensworth, \& Bryk, 2001, p. 299). Instructional Program coherence does not support piecemeal improvements or quick gain methods. These have proven to be short lived too many times. This program does not support innovation overload, referred to as the "Christmas Tree Syndrome" by Anthony Bryk (1998). There is nothing to be gained by schools having too many programs in operation at the same time. What instructional program coherence requires is a clear and strong instructional focus that is schoolwide. It also requires schoolwide commitment and internal accountability. It requires collective efforts involving the whole school community. This involves the teachers, principal, parents, students, and community members working together to improve the school. 
Strong program coherence is evident when three major conditions prevail in a school: A common instructional framework guides the curriculum, staff working conditions support implementation of the framework, and allocation of funding, materials, time, and staff assignments advance the school's common instructional framework. (Newmann, Smith, Allensworth, \& Bryk, 2001, p. 299)

Another important aspect of instructional program coherence is the instructional framework. Schools must develop a common instructional framework that guides the curriculum that is used schoolwide. This requires teachers to come out of the confines of their classrooms, and work together. There is nothing to be gained by teachers closing their doors and teaching whatever he/she decides is important. For academic improvement to be gained, the school must unite and focus on a common instructional framework and curriculum. The school leader must ensure that the school is moving in this direction. Teachers should share strategies and collaboratively develop lessons to maximum learning potential. Next, assessments should be collaboratively developed and used. Assessment data should be analyzed and used to evaluate the effectiveness of instruction and as a catalyst for revisions to curriculum and instruction. The key is that all of these activities are done schoolwide. In fact, each common grade classroom within a school should develop lesson plans together, teach the same curriculum, use the same assessment, and analyze assessment data together for continuous improvements to be realized. These activities should be sustained over time to ensure overall success.

As promising as these strategies of relational trust and instructional program coherence may seem, few schools operate at the level described.

\section{Statement of the Problem}

Many urban schools are failing the students they serve, while other schools in similar urban settings are excelling. For the past quarter century researchers have 
examined various effective school correlates that result in high student performance. These correlates are considered to be important and are frequently incorporated in state mandates and district policies. But adoption of these correlates is only the first step to academic success. Other indigenous factors, such as relational trust and instructional program coherence, must also be considered in any account of sustained high quality school performance. This study examines a high performing school according to the five themes of NCEA and organizational properties of relational trust and instructional program coherence. This study examines contextual factors that contribute to a professional learning community that cultivates the five NCEA themes, relational trust, and instructional program coherence.

\section{Definition of Terms}

To clarify understanding and to assist in the interpretation of the study, the following definitions were applied.

Average Yearly Progress: a measure of a school's or school system's ability to meet required federal benchmarks with specific academic performance standards from year to year.

Ethos of Excellence: the guiding beliefs, standards, ideas, or practices that characterize a group, which results in a high degree of good quality.

Exemplary Urban Schools: schools located in urban areas whose student achievement on the ISAT is greater than $50 \%$ meets or exceeds national norms across a given grade level.

ISAT: Illinois Standards Achievement Test (standardized test). 
Low socioeconomic students: students whose family size and income ratio meets the criteria to qualify them for the free or reduced meal program in public schools

Professional Learning Community: a school's professional staff members who continuously seek to find answers through inquiry and act on their learning to improve student learning.

Relational trust: an organizational property in that its constitutive elements are socially defined in the reciprocal exchanges among participants in a school community.

Student achievement: students' academic growth as measured by standardized testing (ISAT).

Student Performance data: actual student scores on all forms of tests.

\section{Research Questions}

1. To what extent are the five themes of the NCEA Model developed in the high performing school?

2. To what extent is Relational Trust developed in the high performing school?

3. To what extent is instructional program coherence developed in the high performing school?

4. What is the influence of the principal's leadership style on the staff and school climate?

5. How do the five themes of the Illinois Best Practice Framework, instructional program coherence, and relational trust contribute in creating a professional learning community?

\section{Design of the Study}

A qualitative approach was chosen for this study in an effort to document the unique practices that make an effective urban school. The school was examined by observation and interviews according to the five NCEA themes. Two aspects of relational trust (teacher-principal and teacher-teacher) were measured by a teacher 
survey. Instructional Program Coherence was measured using the same survey method. This method involves an item responses scored on a 4-point scale $(1=$ strongly disagree, 4 = strongly agree). The study was conducted in three phases: site identification, fieldwork in the school, and analysis and reporting of data.

Phase I of the study involved identifying a school for the study based on NCEA criteria. Schools were selected for study using NCEA's identification process. NCEA partners recommended schools for site visits based on a regression analysis of school performance over a 3-year period relative to similar schools, with attention to the percent of students tested, and an examination of potential anomalies in state data. In addition, school performance was based on all tested subjects and grades, and the school must have had $50 \%$ or more low-income students.

Phase II of the study involved fieldwork in the school. Approximately 2 weeks were spent in the school conducting classroom observations and in-depth interviews with teachers and the principal. A systematic collection of documents was also made in accordance to the NCEA Best Practice Framework suggested guidelines: (a) curriculum guides for core subject areas, (b) scope and sequence with pacing guides, (c) school improvement plan, (d) teacher interview instruments, (e) documents showing alignment of professional development to identified needs, (f) new teacher programs, $(\mathrm{g})$ teacher evaluation tools, (h) walkthrough documents, (i) school-based student intervention programs, (j) intervention materials for struggling teachers, $(\mathrm{k})$ master schedule, (l) staff meeting agendas, (m) vision and mission statements, (n) sample of school-developed assessment, and (o) lesson plans. 
Phase III of the study involved the analysis and reporting of the data. The observation data, interview data, and documents were examined in an effort to confirm the existence of specific practices as well as to identify other unique practices that may have been discovered. The results are published via the Just For Kids website, "The National Center For Educational Accountability" for Illinois Best Practice Study Framework.

\section{Significance of the Study}

As low socioeconomic student achievement in urban school settings continues to decline and these students consistently score below their more affluent counterparts, educators seek ways to counteract this growing problem. This study examined an exemplary urban school serving similar low socioeconomic student populations to identify the specific practices that contribute to their students' success.

\section{Assumptions}

The results of this study were based on three assumptions:

1. The school targeted for study represents a high quality urban school worthy of careful examination.

2. The respondents will provide accurate and honest answers to the interviewer.

3. The interview questions and answers offer valid and reliable information about the "best practices" in the school.

\section{Delimitations}

This study focused on seventh- and eighth-grade teachers in a high quality urban school. Thus, the findings should be limited to the population from which the sample was drawn. As schools are unique learning communities, the results of this urban school 
cannot be generalized across all schools; however, specific practices identified in the study can be replicated.

\section{Organization of the Study}

This study is organized into five chapters. In Chapter I, the reasoning that undergirded this study was identified within the context of current school reform efforts. Chapter I also included the statement of the problem, conceptual framework, research questions, significance of the study, assumptions, and delimitations of the study. In Chapter II, a discussion of the current literature and the prevailing ideas of top educational researchers will be presented. Chapter III will reveal in detail the methods used to conduct this study. The results of the data analysis will be presented in Chapter IV. Finally, the findings, conclusion, and implications of this study will be discussed in Chapter V. 


\section{CHAPTER II}

\section{REVIEW OF RELATED LITERATURE}

\section{School Effectiveness Movement Beginning}

The Effective Schools Research is built on decades of research studies of high and low performing urban schools. The Effective Schools Movement is based on the assumption that all children should, as a resulting of schooling, learn the basic skills in order to become contributing members of society. It became public knowledge that many students in public schools lacked the skills required by employers. With the need for unskilled labor diminishing, the demand for more educated workers grew. Similarly, global marketing also spurred the need for more highly educated people in the United States. Thus, the blame and pressure was put on K-12 educational institutions.

\section{Federal Involvement Begins}

With Congress passing the "Civil Rights Act" in 1964, which granted equal rights to all citizens, along came demands for equal educational opportunity in public schools for children of all ethnicities. "In conjunction with the Civil Rights Act, Congress provided funding under which James Coleman and his colleagues conducted a national Equal Educational Opportunity Survey. The object was to assess the distribution of educational resources by race..."(Mace-Matluck, 1987. p. 6). The findings of this survey, published in 1966, stated that:

educational resources available to black students closely matched those available to white students... The report also stated that, in spite of availability of similar 
educational resources, black student performance was considerably below that of white students. Coleman's report made a similar observation about performance differences between affluent and poor students. (Mace-Matluck, 1987, p. 6)

According to Mace-Matluck (1987), Coleman's report controlled statistically for school factors and then argued that a family's socioeconomic background is more directly related to a student's academic performance than factors within the school. Another researcher analyzed the highly controversial findings from the Coleman Report and concluded, "The Coleman researchers' use of verbal ability as the primary dependent measure resulted in an underestimate of the effect of schools on student achievement" (Marzano, 2003, p. 7). After a reinterpretation of the Coleman study, Marzano (2003) went on to establish "The logical conclusion to draw from the Coleman Report, then, is that effective schools do make a difference in student achievement" (p. 6). Marzano continues to synthesize the results of other researchers and he concludes, "that the average finding was that schools account for 20 percent of the variance in student achievement- twice as much as reported by Coleman" (p. 7). Although the Coleman Report was controversial because it was said to have methodological problems and Coleman in later years refined his earlier findings, the report redefined the research agenda for a generation of educational researchers, and it triggered The Effective Schools Movement.

\section{Search for Effective Schools}

After the blistering Coleman Report, educational researchers began to search for schools that were effectively teaching students from minority and poor family backgrounds. In fact,

For four decades now, scholars have poked and probed at the workings of schools, trying to determine the essential factors that create an effective school. Triggered by the landmark Coleman Report, Equality of Opportunity (Coleman et 
al., 1966), which concluded that socioeconomic factors matter more to student outcomes than the work of schools, the search was on for evidence that schools actually do matter in the lives and fortunes of students. (Curry, Pacha \& Baker, 2006. p. 1)

An early study, cited by Mace-Matluck (1987) and conducted by researchers Klitgaard and Hall (1974), did in fact reveal effective schools. "Their 1974 report is important for historical as well as substantive reasons: it was the first rigorous, largescale effort to identify effective schools" (Mace-Matluck, 1987, p. 8). These researchers "used student performance on standardized reading and mathematics achievement tests as their measure of school effectiveness" (Mace-Matluck, 1987. p. 8). According to MaceMatluck (1987), they analyzed three large-scale data sets from Michigan, New York City, and the 1960 Project Talent high school data. "With student background factors controlled statistically, they found schools in which students consistently achieved at higher-than average levels. The data also revealed unusually effective school districts" (Mace-Matluck, 1987.p. 8). Although the high performing schools represented only a small percent $(2 \%-9 \%)$, of the sample, these schools were clearly more effective than other schools serving similar student populations. While most schools followed the pattern predicted by Coleman, important exceptions were formed that challenged the Coleman thesis. These schools are often identified as outliers.

Another important study to identify effective schools and their unique characteristics was conducted by researcher George Weber (1971). Weber selected four innercity schools serving low-income student populations with successful reading achievement to conduct his case studies. In his findings, Weber (1971) cited similar characteristics that he discovered in the four successful schools; all four schools had strong leadership, high expectations, an orderly quiet atmosphere, and emphasized reading skills (Edmonds, 
1979). Weber's findings were yet another scholarly study in sharp contrast to the landmark Coleman Report, which suggested that minority and poor students could not learn because of their family background. Edmonds (1979) agreed with Weber's early results stating: "My own view is that Weber was essentially correct both in concept and basic research design, considering the relative modesty of his enterprise" (p. 16).

Other studies followed that continued to confirm and expand the effective schools characteristics that Weber (1971) revealed in his study. The Michigan Department of Education asked Brookover and Lezotte to study a set of contrasting Michigan schools, some characterized by student improvement and others by poor student performance. The researchers chose eight schools to study (six improving, two declining). The study revealed stark differences in school practices, including emphasis on improvement, teacher expectations for students, emphasis on mastery of basic skills, leadership, parent involvement, use of paraprofessional staff, and students placed in compensatory education programs. These early studies identifying effective schools and the similar characteristics that they share led to a new era in educational studies and improvement programs. Now researchers sought to develop these Effective School characteristics into programs or approaches that educators could use to improve their schools. Edmonds conducted his own research as well as analyzed studies done by other researchers. As a result of his studies, Edmonds refined the earlier Effective School characteristics into what he called Effective School Correlates. He called them "Correlates" because he felt that the correlates were indispensable and interdependent. As a result of his studies, Edmonds stated that, "There has never been a time in the life of the American public school when we have not known all we needed to in order to teach all those whom we 
chose to teach" (1979, p. 16). In fact, Edmonds thesis was “...that all children are eminently educable and that the behavior of the school is critical in determining the quality of that education" (p. 20). Edmonds believed very strongly that, when school leaders wanted to, they could, in fact, teach the poor and minority children with success.

With so many research studies emerging on school effectiveness, many educators began implementing the Effective School approaches with hopes of improving their schools but realized little success. Educational researchers continued to study both high and low performing schools, but the perspective of the studies began to vary from a concentration on student learning to issues of accountability (e.g., school leadership and organization, quality of instruction and professional development as educators) continued their quest to improve schools for all students.

\section{Implementing Effective School Principles}

An ambitious national program to implement the principles of effective schools was launched by the National Center for Educational Accountability (NCEA). NCEA engaged educational researchers in 11 states to study high-performing schools.

According to Luce and Thompson (1997),

These studies, organizations, and initiatives all reflect a promising and significant development in our nation's efforts to improve our schools. Increasingly, there is a focus on (1) pinpointing what is working and why, (2) disseminating information to educators concerning these practices, and (3) encouraging educators to adopt these effective tools. (p. 60)

The NCEA project developed a Best Practice Framework of five organizing themes based on findings from past effective schools research.

The Best Practice Framework thus provides a structure for communicating what high-performing schools systems at three levels (district, school, and classroom) are doing to get results. This usable organizational tool supplies access not only 
to a listing of best practices, but also to a full set of tools that facilitate enactment of practices. (Luce \& Thompson, 1997, p. 70)

The five NCEA Themes are as follows: (1) Curriculum and Academic Goals, (2) Staff Selection, Leadership, and Capacity Building, (3) Instructional Programs, Practices, and Arrangements, (4) Monitoring and Use of Data, and (5) Recognition, Intervention, and Adjustments. These five themes form the core framework used to conduct and report this dissertation study. Each theme is reviewed as a set of critical issues in the school improvement literature.

\section{Curriculum and Academic Goals}

Clearly stated, curriculum and academic goals establish a focus for schools to organize instructional activities. This type of organization takes the guesswork out of lesson planning. These goals should drive the teaching and learning processes. It is also important that these goals are aligned to state learning goals. According to researchers who conducted an extensive study of high and low performing schools in the Chicago Public School System, "Schools should be driven by a coherent system of educational goals. Content standards would define the knowledge to which students should be exposed, and would include explicit criteria for judging student performance" (Bryk, Sebring, Kerbow, Rollow, \& Easton, 1998, pp. 13-14). Another study using research data from Chicago Public Schools revealed greater student achievement gains in schools with more coherent instructional programs (Newmann et al,, 2001). According to this study, teachers within a grade connected their entire curriculum to the established academic goals developed based on the state learning goals; teachers coordinated curriculum and assessments across the grade levels; school-sponsored programs such as fieldtrips supported the curriculum, instruction and assessments; and professional development for 
staff supported the implementation of a common curriculum, instructional strategies, and assessments (Newmann et al., 2001). Newmann et al. also found that the curriculum should remain reasonably stable over time in order to provide teachers with sustained opportunities to learn how to teach it well. Sustaining programs, curriculum, and even staff have proven to be a major challenge for many schools, especially those in economically depressed areas.

\section{Implementation Challenges}

In reflecting on students' academic achievement, it makes sense that there should be specific academic goals based on state standards at each grade level with connected assessment to monitor student mastery of the stated goals. However, research has revealed that this has not been the norm for many schools (Luce \& Thompson, 1997). Many of the low performing schools lacked clear academic goals, and teachers taught according to topics found in the textbooks. This lack of focus has resulted in inadequate coverage of curriculum in many failing schools across this nation. According to Luce and Thompson (1997), the NCEA study revealed that high-performing schools establish clear, specific academic goals that apply to all students at every grade level and, moreover, all teachers know and agree upon these learning goals and are held accountable for students attaining them. The NCEA studies also revealed that the high-performing schools were well supported by

districts that clearly know what the end goal is for each student in each subject and in each grade. Thus educators at the district level - as well as educators in each district school and classroom - are very familiar with what each student should know by the end of the school year. (Luce \& Thompson, 1997, p. 91)

In fact, after the passing of the No Child Left Behind of 2001, many schools began to look more closely at the curriculum that was linked to state exams. Initially, 
struggling schools began to narrow the focus of their curriculum and increase instruction in reading and math with hopes of improving student achievement on the state standardized tests. As a result, school curriculums became highly test-driven and the joy of learning was lost for many students. This approach, along with many other quick-fix programs born out of desperation, did little to improve student achievement and left struggling schools no better off. While educators recognized the importance of having clear and precise academic goals, it was also necessary to implement goal setting with instructional strategies to motivate both teachers and students.

\section{Staff Selection, Leadership and Capacity Building}

\section{Staff Selection}

Staff selection is an integral process in creating effective schools. Having good teachers has long been touted as a major factor in effective schooling.

In virtually every instance in which researchers have examined the factors that account for student performance, teachers prove to have a greater impact than program. There is an enormous amount of evidence that teachers have a significant impact on efforts to change schools.... (Darling-Hammond, 1999, p. 128)

This belief is also reflected in the No Child Left Behind Legislation (2001), which mandated schools to employ "highly qualified" teachers and staff in every aspect of schooling.

In their study, Luce and Thompson (1997, p. 94) found that, "Each of the highperforming schools clearly realized the central necessity of having educators who have the capacity to empower students to reach those goals." Teachers actually work more closely with the students than any other school personnel; therefore, it makes sense that teacher skill and knowledge should be of high quality. One prominent researcher states, 
"The level of expertise among teachers is important. It determines the starting point for work on instructional issues and, hence, the professional development capacity of schools" (Elmore, 2002, p. 19). Experience and research have revealed that it takes more than hiring a person with the prescribed academic credentials. Administrators have come to recognize the importance of finding teachers who are willing to commit to working collaboratively, as well as embrace new instructional strategies and school improvement efforts. According to the research, "These high-performing districts stress finding teachers that fit the needs of particular district schools; aggressively recruit and train superior educators; and then provide ongoing and effective support and professional development to teachers" (Luce \& Thompson, 1997 p. 96). While research has established the importance of teachers to the continued improvement of schools, the same can be said for school leaders.

\section{Leadership}

The principal is the school leader who sets the tone as well as the professional standards and academic climate in the school. The school principal organizes and facilitates all activities that happen in the school. Most would agree that school activities such as curriculum and instruction should be top on the list of priorities. While the teachers actually deliver the instruction to students, "a school principal's primary responsibility is to be an instructional leader" (Luce \& Thompson, 1997 p. 96). School principals must recognize the importance of supporting teachers with the training that is needed to improve instruction. Research quoted earlier in this text established the importance of having highly qualified teachers in student achievement. It can be argued that it is equally important to have highly qualified school principals as well. Moreover, 
research supports the practice of professional development for principals along with teachers. These researchers believe that "professional development can enhance principal leadership" (Newmann, King, \& Youngs, 2000, p. 264). It is important to note that in these high-performing districts the school principal also receives on-going professional development and mentoring. This practice does not assume all principals come as experts to their jobs and leave nothing to chance. "The high-performing schools provided tailored, ongoing, and high-quality support to all principals, both new hires and experienced veterans, for example, a Principal Mentor Program that provides 3 years of mentoring for new principals by distinguished retired principals" (Luce \& Thompson, 1997, p. 96). School leaders who provide support for teachers and participate in mentoring programs themselves are increasing the school's potential for success by building the capacity of their staff to perform their duties better.

\section{Capacity Building}

The key concept resonating from leadership is development of principal leaders who are savvy enough to recognize the power of providing as well as engaging in strategically targeted professional development that will build the capacity of the entire school staff in order to improve instruction. According to research, "Student achievement is affected most directly by the quality of instruction. Instruction, in turn, is affected by school capacity, and capacity is affected by actors who sponsor policy or programs" (Newmann, King, \& Youngs, 2000, p. 261).

School capacity includes the knowledge, skills, and dispositions of individual staff members. School capacity requires effective principal leadership. In most schools, the principal has the legal authority to affect each aspect of capacity, for better or worse depending on the quality of leadership. (Newmann, King, \& Youngs, 2000, p. 263) 
Another group of educational researchers defines capacity as: "The collective power of the full staff to improve student achievement schoolwide can be summarized as school capacity" (Newmann, King, \& Youngs, 2000, p. 261). This is a new school of thought for professional development. This way of thinking about professional development attempts to address a school's weaknesses rather than an individual's weaknesses. In fact, researchers believe that "professional development can affect all aspects of capacity" (Newmann, King, \& Youngs, 2000, p. 264). Moreover, in this broad study it was revealed that,

All of the identified high-performing urban districts build up the capacity of their staff in three vital ways: first, they develop and support strong instructional leaders, including each school's principal; second, they hire and support highly qualified teachers; and, third, they provide high-quality professional development that is closely aligned with the staff's instructional needs" (Luce \& Thompson, 1997 p. 96)

As the focus of professional develop has changed to a more holistic view, it remains a very important vehicle for school improvement. Research continues to confirm the positive effects of professional development as reflected in this statement, "Because of continuing challenges even to high-capacity urban schools that serve low-income students, comprehensive professional development seems necessary to sustain and enhance that capacity" (Newmann, King, \& Youngs, 2000, p. 291). Research in school settings shows that there is no magic quick fix program for the challenges of educating under achieving students in poor urban schools districts, but it requires strategically chosen strategies for on-going professional development for administrators and teachers. One team of researchers concluded their study with the following comment: "The main implications of these findings are (a) it is possible for urban elementary schools serving low-income students to organize professional development to address school capacity 
comprehensively, and (b) this can be accomplished through diverse approaches"

(Newmann, King, \& Youngs, 2000, p. 291). Strengthening instructional programs, practice and arrangements is one approach to improving schools.

\section{Instructional Programs, Practices, and Arrangements}

\section{Instructional Programs}

The instructional program refers to the replicable instructional activities and the selected curriculum that are designed to reach students' learning goals. The instructional program is of great importance in the school improvement process because instructional practices link teaching efforts to the achievement of curricular standards. Effective instructional programs are desperately sought after by poorly performing schools. To quote a team of researchers, "Over the past decade, many poorly performing elementary schools have sought to improve their instructional programs and outcomes by adopting numerous school improvement projects, programs, and partnerships (Newmann, Smith, Allensworth, \& Bryk, 2001, p. 297). These programs often fail to produce the desired results and fade while new programs replace them. To illuminate this problem even further, Michael Fullan (2001) states, "The main problem is not the absence of innovation in schools, but rather the presence of too many disconnected, episodic, fragmented, superficially adorned projects" (p. 21). Another prominent researcher based in Chicago, Illinois, referred to this problem of innovation overload in schools as the "Christmas tree problem" (Bryk \& Associates, 1998). Newmann et al. (2001) believes this practice of choosing too many programs fragments the staff as well the instructional program. "Staff divide themselves among various initiatives and direct a great deal of time and energy into multiple workshops, meetings, and conferences" (Newmann, Smith, Allensworth, \& 
Bryk, 2001, p. 298). Again, all these misguided efforts often lead to no gains and lots of wasted time. Experience and failed efforts have shown educators that instructional practices and arrangements should be strategically planned.

\section{Practices and Arrangements}

Research reveals that high-performing schools use a different approach to choosing instructional programs. According to Luce and Thompson (1997), "All of the high-performing districts only implement programs that will enable their students to meet the academic objectives that the district has clearly set out. Hence, why these districts establish their academic goals before establishing their academic programs" (p. 100). This practice seems more logical, because it sets the criteria from which to choose a particular instructional program to meet the needs of a particular group of students. To emphasize the importance of the proper instructional program, Luce and Thompson (1997) revealed, "These high-performing schools only implement instructional programs that are proven to bring about academic achievement gains among groups of students that are demographically similar to their own district's students" (p. 100). Luce and Thompson (1997) went on to comment that these high-performing schools districts pilot new instructional programs in their own schools to ensure the effectiveness of the new instructional programs with students before they are approved for widespread use.

Another practice revealed in the literature involves analyzing student test data then using the information to ensure the most effective instructional practices are sustained while those less effective ones are dropped. To quote Luce and Thompson (1997),

All of the high-performing school districts ensure that the instructional programs are well-tailored to empower their students to meet these academic objectives, the districts employ student performance data so that they can pinpoint what the specific needs of district students are. (p. 100) 
The use of student performance data has gained great popularity in schools today as educators experience the power that this knowledge can give when making strategic decisions about instructional programs, practices, and arrangements.

\section{Monitoring: Compilation, Analysis, and Use of Data}

Indeed, the use of student performance data has proven to be a valuable tool in the realm of school improvement. As stated in the literature, "Of central importance to all of the high-performing school districts is their comprehensive and highly relevant system of assessing and monitoring student and teacher performance" (Luce \& Thompson, 1997, p. 102). According to these research findings, teachers as well as students are monitored to chart progress or the lack there of. These schools use current performance data on both teachers and students in order to provide whatever support is needed to enable students to perform at higher levels. To analyze this approach,

Three elements are central to the assessment and monitoring approach in these high-performing districts: a complete and accessible district data system of student performance information; ongoing monitoring of student and teacher performance through benchmark assessments and teacher evaluations; and the use of student performance information to set goals, evaluate progress toward achieving them, and adjust instructional practices to spur that progress. (Luce \& Thompson, 1997, pp. 103-104)

Another common practice in schools used for monitoring teachers and students is a procedure called a walkthrough. Walkthroughs are a simple procedure whereby a school leader or designee walks into classrooms and quietly observes instructional techniques and student engagement. The walkthrough is usually short in duration but can reveal valuable information about the teaching and learning process. In one of the highperforming schools, district staff follow detailed guidelines as they conduct "focused instructional walkthroughs" at schools to evaluate teachers and administrators. These 
walkthroughs serve to gather data not available elsewhere about teaching techniques and student learning" (Luce \& Thompson, 1997 p. 105). Systematic data collection and analysis provides essential information to assess the school's strengths and weaknesses and make informed decisions in regard to curriculum, instruction, and program choices. Monitoring teachers and students also enables schools to recognize successes or intervene as needed.

\section{Recognition, Intervention, and Adjustments}

\section{Recognition}

Who would not benefit from recognition of one's successes or strategic intervention when it is needed? From life and work experiences, one can clearly reflect on how recognition of one's successes can not only motivate the achiever to greater success but also those peers who are in school. This is why it is important to recognize the hard work of teachers and students, the motivational gain for all. "A fifth area of practice is also central to the high-performing schools' success: rewarding those schools that achieve student performance goals and providing assistance intervention to schools that display weaknesses in student performance" (Luce \& Thompson, 1997, p. 105). Life experiences have shown that all to often the bad news of school failure makes a greater, more lasting impact in the media and the good things are left untold. According to Luce and Thompson, "Although we more commonly hear about how districts assist or sanction schools when student achievement is poor, the high-performing schools realize that rewards for high performance are just as integral to eliciting student achievement" (p. 106). They go on to argue that rewards for high performance teachers are just as integral to eliciting mediocre teachers to work harder and smarter. A school district illustrates 
their point: "Norfolk Public Schools encourages effective teaching through annually awarding a Teacher of the Year and an All-City Teaching Team" (Luce \& Thompson, 1997, p. 106). According to NCEA researchers, this practice of awarding teachers has spread and is gaining momentum as media has now begun to publicize good school news. All across the United States one can hear of students, teachers, or principals being recognized for high performance in education.

Likewise, researchers found that, "Boston Public Schools understands the importance of recognizing principals whose schools attain high performance; principals at schools that make considerable achievement gains in English language arts and math receive incentive bonuses" (Luce \& Thompson, 1997, p. 106). As research data supports, recognition of one's accomplishments goes a long way to motivate and inspire others to strive harder, and this is a good practice for the field of education.

\section{Intervention and Adjustments}

Intervention and adjustments are just as important to a school or student's success as any other practice. As educators come to recognize this very crucial fact, intervention systems have been developed to aid struggling students. According to research, "The high-performing districts also realize how vital support is to those schools and students who are not meeting achievement goals. They rely on disaggregated student data to determine which students need extra help to improve their performance" (Luce \& Thompson, 1997, p. 106). In fact, student performance data gives detailed facts on a student's strengths and weaknesses. Researchers cite a district educator's comment about their practice: "The best intervention begins with a good diagnosis of what students are able to do, so the district puts a heavy emphasis on the use of disaggregating your data to 
see how schools, classrooms, and individual students are performing" (Luce \&

Thompson, 1997, p. 106). From this performance data, individual intervention plans can be developed that specifically address a student's needs. One school principal and his staff developed an intervention system to aid struggling students. He shared his experiences as follows:

Attention to student mastery enabled us to identify specific students who were having difficulty acquiring the intended knowledge and skills. The staff then worked together to build an intervention system that provided struggling students with more time and support during the school day. We assigned a faculty advisor to every incoming student to monitor his or her learning. Counselors met with freshmen every week. We issued academic progress reports in each course every three weeks. When we identified a struggling student, his or her advisor and counselor worked together to develop a plan of response. This systematic response to those who were not learning made it clear to both students and staff members that we expected all Stevenson students to learn. (Dufour, 2002, p. 15)

In the past, struggling schools were faced with criticism and sanctions, but now school districts are providing more support to struggling schools. In fact, research revealed that “... when specific prescriptive standards connected to high-stakes consequences are mandated by external authorities, this can deny school staff both the 'ownership' or commitment and the authority it needs to work collaboratively to achieve a clear purpose for student learning" (Newmann, King, \& Rigdon, 1997, p. 62). Researchers found that, The districts determine which are the struggling schools and focus resources on them. Long Beach district determines which schools are low-performing, "focus schools" each year, and then devotes district office personnel who have expertise in the relevant content area to those schools to give hands-on support. (Luce \& Thompson, 1997, p. 107)

According to NCEA Best Practices, districts providing additional support to struggling schools will more than likely go further to help improve the school than negative sanctions can ever do to help the problem. Relational trust is an often overlooked factor that can negatively impact a school's efforts to improve. 


\section{Relational Trust}

Bryk and Schneider (2002) studied the dynamics of relational trust in improving schools. Over a 3-year period this team of researchers conducted extensive observations and interviews in 12 different elementary schools in Chicago, Illinois. As the team analyzed the data, they became aware that the social relationships within schools were impacting whether or not schools made good use of their newly acquired autonomy and resources. Since there was little formal research on this topic in education, the research team looked outside of the realm of education to develop a theoretical framework for analyzing social trust at the school level. Three schools were systematically analyzed based on this conceptual framework for relational trust.

Although social dynamics is a not new concept in education, "A growing body of case studies and narrative accounts about school change direct our attention to the social dynamics of schooling, and especially to the engaging but also somewhat elusive idea of social trust as foundational for meaningful school improvement" (Bryk \& Schneider, 2002, p. 8). They elaborate on the place of trust in schools by identifying a central set of relationships. "Relational trust views the social exchanges of schooling as organized around a distinct set role relationships: teachers with students, teachers with other teachers, teachers with parents and with their school principal" (Bryk \& Schneider, 2002, p. 20). The collective power gained is the direct result of people choosing to work together in a cooperative spirit. According to the researchers, "The effective functioning of democratic institutions rests heavily on the willingness of citizens to associate voluntarily with one another to redress collective concerns" (Bryk \& Schneider, 2002, p. 13). The key concept is the willingness of all stakeholders to coalesce and work toward the 
improvement of the whole school. Research revealed that, "The presence of relational trust among a faculty allows it to coalesce as a professional community where teachers can undertake genuine collective work together" (Bryk \& Schneider, 2002, p. 116).

One important trust relationship in schooling is between the teacher, student, and parent. These case studies revealed how teacher, student and parent interactions can impact student attendance and personal efforts exhibited toward schoolwork. "The personal dynamics among teachers, students, and their parents, influence whether students regularly attend school and sustain efforts on the difficult tasks of learning" (Bryk \& Schneider, 2002, p. 5). In fact, when there is a mutual relationship of trust between teachers and parents, there is less chance that students will exhibit off-task behaviors and teachers feel free to contact these parents after hours if there are any problems. This type of parental support helps tremendously in students' academic progress.

Relational trust does not directly affect student learning. Rather, trust fosters a set of organizational conditions, some structural and others social-psychological, that make it more conducive for individuals to initiate and sustain the kinds of activities necessary to affect productivity improvements. (Bryk \& Schneider, 2002, p. 116)

Relational trust breaks down the barriers of teacher isolation and promotes a teamwork spirit often found in professional sports teams. When teachers develop mutual trust in each other's ability to do one's work, and respect for each other's ideas and begin to share these strategies with each other, the benefits are immeasurable. The presence of relational trust offers opportunities for teachers and administrators to become learners and thus improve one's craft; teaching. Upon presenting their research results, the researchers concluded with this statement, "Clearly, relational trust matters as a resource for school improvement" (Bryk \& Schneider, 2002, p. 121). Instructional program 
coherence is another factor that greatly impacts a school's potential for success.

\section{Instructional Program Coherence}

In a major study of Chicago elementary schools, Newmann, Smith, Allensworth, and Bryk (2001) found that successful schools seemed to have more instructional program coherence than less successful schools. These educational researchers designed a study to learn more about the impact of greater instructional program coherence on student achievement. This 2-year empirical study involved over 5,000 teachers completing surveys designed to measure a broad range of instructional programs and practices. Field studies were conducted in 11 elementary schools located in neighborhoods throughout Chicago. The study used student achievement data from the Iowa Test of Basic Skills to measure student achievement gains.

As defined in the study, "Instructional program coherence is a set of interrelated programs for students and staff that are guided by a common framework for curriculum, instruction, assessment, and learning climate and that are pursued over a sustained period" (Newmann, Smith, Allensworth, \& Bryk, 2001, p. 299). Instructional program coherence does not support piecemeal improvements or quick gain methods. In fact, these piecemeal strategies have often proven to be short lived. Bryk refers to this eclectic practice as the "Christmas Tree Syndrome" (1998). There is nothing to be gained by schools having too many programs in operation at the same time. In fact, research reveals that this actually does more harm than good by dividing the staff between these programs thus fragmenting the school's instructional program.

What instructional program coherence requires is a clear and strong instructional focus that is school wide. 
Strong program coherence is evident when three major conditions prevail in a school: (1) A common instruction framework that guides curriculum, teaching, assessment and learning; (2) Staff working conditions support implementation of the framework; and (3) Allocation of funding, materials, time and staff assignments advance the school's common instructional framework. (Newmann, Smith, Allensworth, \& Bryk, 2001, pp. 299-300)

An important focus of instructional program coherence is the school's instructional framework. Schools must develop a common instructional framework that guides the curriculum and that is used school wide. This requires teachers to come out of the confines of their classrooms and collaborate. For academic improvements to be gained, the school must unite and focus around a common instructional framework that guides curriculum, teaching, assessment, and the learning climate. The school leader must ensure that the school is moving in this direction. Teachers should share strategies and collaboratively develop lessons to maximize students' learning potential. Next, common assessments should be collaboratively developed and used. Assessment data should be analyzed and used to evaluate the effectiveness of instruction and as a catalyst for revisions to curriculum and instruction. The key is that all of these activities are done school wide. In fact, each common grade classroom within a school should develop lesson plans together, teach the same curriculum, use the same assessment, and analyze assessment data together for continuous improvements to be realized. These activities should be sustained over time to ensure overall success.

The central question guiding this study was whether schools with improving instructional program coherence also showed improvements in student achievement. The results of the study revealed, "A strong positive relationship between improving coherence and improved student achievement. Schools that improved their instructional program coherence between 1994 and 1997 demonstrated improved student test scores 
over the same period of time" (Newmann, Smith, Allensworth, \& Bryk, 2001, p. 305).

As simplistic as these strategies of strong instructional leadership and instructional program coherence may seem, few schools operate at the level described. School leaders face many barriers to realizing sustained school improvements. School leaders are hindered greatly in their work by the relentless flow of mandated changes from above (Baker, 1999). Baker also suggests that the changes lack meaning for those who are responsible to carry them out. It seems that teachers are not prepared for the mandated changes that call for new instructional strategies and their professional development sessions lack meaning as strategies that would prepare them. Thus, the problem of how to improve the education for poor and minority students trapped in low performing schools continue to plague many educators.

\section{Principal Leadership}

In a 5-year study of 24 restructuring schools across the United States, Newmann, King, and Rigdon (1997) sought to measure the impact of external accountability on school performance. The central question of their study was: "Will increased accountability of schools to external agents improve school performance throughout the United States?"' The study revealed that "even when strong external accountability can be established, the performance of many schools could languish for lack of school organizational capacity" (Newmann, King, \& Rigdon, 1997, p. 62). In essence, the study results indicated that a lack of organizational capacity in schools result in poor student achievement.

Given the pervasive nature of externally mandated accountability in the name of improvement school performance, the implications for school leaders who want to improve their schools call for strong organizational capacity and instructional leadership 
that promotes instructional program coherence. In fact, "Stronger instructional program coherence was rooted in a principal's decision to adopt or develop a schoolwide instructional program framework and to make it a priority" (Newmann, Smith, Allensworth, \& Bryk, 2001, p. 306). Newman, King, and Rigdon (1997) suggest that many schools lack organizational capacity and thus are rendered unable to improve the academic achievement of students. Newman, King, and Rigdon (1997) believe that no external mandates can be realized until a school's organizational capacity is improved. Moreover these researchers believe that external accountability should first seek to support the improvement of a school's organizational capacity before any sustained academic improvements can be realized.

Newmann, King, and Rigdon (1997) define organizational capacity as "the degree to which the human, technical, and social resources of an organization are organized into an effective collective enterprise" (p. 47). School leaders who want to improve their schools must build organizational capacity within the school. "Proposed ingredients of organizational capacity include teachers' professional knowledge and skills, effective leadership, availability of technical and financial resources, and organizational autonomy to act according to demands of the local context" (Newmann, King, \& Rigdon, 1997, p. 47).

One critical aspect of organizational capacity is the formation of a collective enterprise that brings many people together as a working unit. The school leader must build and nurture a collective school climate. Fullan (2001) argues: "The principal is the person most likely to be in a position to shape the organizational conditions necessary for success, such as the development of shared goals, collaborative work structures and 
climates, and procedures for monitoring results" (p. 83). This is accomplished by establishing a clear focus of goals and school mission that all stakeholders help to create. It is important that all stakeholders in the school share in the development of the school's mission statement so that overall acceptance and commitment will be ensured. "For schools, the key to effective coordination and organization of these resources is shared commitment and collaboration among staff to achieve a clear purpose for student learning" (Newmann, King, \& Rigdon, 1997, p. 47). This seemingly simple task, but yet so very important, is the beginning of a collective school climate from which all other school improvements can emerge.

Another important aspect of organizational capacity is strong and effective school leadership. It is effective leadership that must organize the staff and establish internal accountability. Newmann et al. (1997) argues that the concept of accountability implies strong influence by an agent (a school leader). This agent sets standards for performance and issues rewards or sanctions. Fullan (2001) quotes Elmore (2000) that "In the panoply of rewards and sanctions that attach to accountability systems, the most powerful incentives reside in the face-to-face relationships among people in the organization, not in external systems" (p. 254). It is important to note that the school leader must first gain an overall staff commitment to the goals of the school. Then, internal accountability grows out of clear expectations that are communicated and modeled by the school leader. High professional standards start with the school leader exhibiting them and communicating them to the staff. Next, an effective leader must establish an internal monitoring system in the school and keep the staff informed while also managing the multitude of external mandates and changes that this era of accountability has demanded. External account- 
ability also mandates significant increases in student achievement. Consequently, a school leader must establish a strong instructional program as well as monitor teachers and student progress. It is important to establish and chart student progress on an ongoing basis.

External accountability calls for "highly qualified" teachers. Therefore, the principal must select teachers for hire based on externally mandated criteria as well as his/her internal commitment to the school's instructional framework. Upon hiring, teacher effectiveness should be monitored on an ongoing basis. Monitoring teacher effectiveness is an important aspect of principal duties and school improvement. Teachers work more closely with the students and can directly promote or hinder the success of many students. Therefore, it is most important that school leaders ensure teachers have the professional knowledge and skills to do their jobs. There should be a continuous, ongoing monitoring, assessment, evaluation, and revision process at work in schools. Most importantly, the staff should be informed on an ongoing basis so that continuous improvements can occur. The effective school leader will seek to meet the needs of the staff by providing ongoing, job-embedded professional development. When monitoring reveals deficiencies in staff, a school leader must provide remediation via professional development or mentoring. It is most important that the deficiency be addressed as quickly as possible because student learning is at risk. Professional development is best when it is provided to meet specific needs and is job embedded. To quote researchers, "We found that comprehensive use of professional development over time was strongly related to the school's initial capacity and to principal leadership that channeled professional development in this direction" (Newmann, King, \& Youngs, 
2000, p. 281). This means that the professional development activities are directly related to the specific needs derived from teaching and learning.

An effective school leader must make significant investments in high quality technical resources, instructional materials, and programs. Resources must be used to support the instructional program (Newmann, 2001). In Newmann's empirical study of several schools, "A feature that distinguished the high-and-low coherence schools was significant investment in instructional materials and programs, including staff training and development..." (p. 311). That same study revealed that low performing schools invested in diverse programs and technical equipment but did not add a training component for the staff. A common practice for many schools involves the delivery of new programs and equipment with limited training available; all too often the new materials collect dust on a shelf somewhere in the school. This study revealed that,

When compared to principals in the lowest ranked schools, principals in the highest ranked schools maintained a more consistent focus for schoolwide professional development rather than leaving most choices about professional development up to individual teachers. They channeled funding and outside expertise to serve the schoolwide focus and "buffered" teachers from outside mandates or reform initiatives that might otherwise interfere. (Newmann, King, \& Youngs, 2000, p. 283)

So the key factor in the idea of channeling resources is to choose programs that support the instructional program and buy the additional training component. With the organizational capacity firmly in place a school leader can begin the process of establishing a professional learning community.

\section{Professional Learning Community}

A critical concept, developed in the past two decades, that compliments the effective schools movement is the professional learning community. According to 
DuFour, Eaker, and DuFour (2005):

The concept of the professional learning community was not part of the school improvement lexicon when the Effective Schools journey began. ...Clearly, continuous school improvement based on the Effective Schools research is an example of professional learning communities in action. (p. 190).

A professional learning community is an organizational arrangement in a school where teachers and administrators establish collegial relationships to continuously seek and share learning and then act on what they learn in order to improve the teaching and learning process for students. Marks and Louis (1999) describe characteristics of professional learning communities as:

Professional communities depart from the normal practice in schools in that teachers do not work in isolation but collaborate within a professional culture. Reflective dialogue, open sharing of classroom practices, developing a common knowledge base for improvement, collaborating on the design of new materials and curricula, and establishing norms related to pedagogical practice and student performance are hallmarks of the professional culture and demonstrably related to student achievement. (p. 713)

"Learning communities are found in classrooms and schools where everyone (students, teachers, administrators, parents) is a teacher and a learner" (Baker, 1996, p. 3). In a professional learning community, the school leader shares school leadership by inviting staff input in the decision-making process especially involving the instructional framework. Moreover, "leaders in learning organizations are responsible for building organizations where they are continually expanding their capabilities to shape their future; that is, leaders are responsible for learning" (Senge, 1990, p. 9). This type of learning involves administrator, teachers and students. The learning used to address school improvement initiatives involves all staff and is collective. Research literature has shown that effective professional learning communities also have a shared vision that is developed from the staff's commitment to students' learning. Effective professional learning communities 
provide coaching, support, assistance, and feedback for teachers to ensure continuous improvement. Baker (1996) quotes Senge (1990) in suggesting: "Part of the meaning of membership in a learning community is the willingness of all participants (regardless of formal titles) to see themselves as learners who are open to inquiry" (p. 3).

In contrast, Senge (1990) asks the question, if professional learning communities are so widely preferred, then why don't people create such organizations? Baker (1996) answers that question by suggesting that building a learning community is not a lone effort of the leader or teacher, and the collective effort is not an easy task. Building learning communities requires everyone's participation to make changes in the way schooling is done. According to Elmore (2002), "improving instructional practice requires a change in beliefs, norms and values about what it is possible to achieve as well as in the actual practices that are designed to bring achievement" (p. 18). Learning communities are built through guided participation and the planned change process that is well thought out and organized (Baker, 1996). "Planned change must be understood as a systemic process that involves the willingness and ability of numerous people who assume new roles" (Baker, 1996, p. 5). In fact, "schools would have to become learning environments for teachers as well as for students. The instructional day would be designed to facilitate the learning of both groups, and the learning of educators, inside and outside of the classroom..." (Elmore, 2002, p. 26).

Building a professional learning community starts with the school leader. The school leader must work with others to establish an organizational culture that supports students, teachers, parents and administrators as teachers and learners. To quote one researcher, "Leadership is intertwined with culture formation. Building an organization's 
culture and shaping its evolution is the unique and essential function of leadership" (Senge, 1990, p. 10). The first task involves creating a shared vision that establishes core values and goals. "Principals of a learning community engage the faculty in the cocreation of shared vision and values" (DuFour \& Eaker, 1998, p. 184). Senge (1990) believes that "when more people come to share a vision, the vision becomes more real in the sense of a mental reality that people can truly imagine achieving." Through shared vision, the leader brings the entire school community together as partners. In fact, Baker, (1996) contends that "the capacity to open up new opportunities of partnership among teachers and parents rests on the willingness of the principal to redefine her role as a bridge builder who searches for endless ways to connect school and home" (Baker, 1996, p. 6). The school leader is also the key person to guide the participation and collaboration of teachers in the change process.

Change is always a threat when it is done to people, but it is an opportunity when it is done by people. ... To be effective agents of change principals of learning communities disperse power throughout the school to teaching teams and ad hoc committees. (DuFour \& Eaker, 1998, p. 186)

Relationships between teachers and the leader must be established and nurtured through planned activities. In essence, the first initiative solely depends on the interests and efforts of the school leader acting as a "bounder spanner" bringing together students, parents, and teachers to build a learning community (Baker, 1996).

The teacher has an important role in the development of a learning community. Schools are effective because of their teachers, not in spite of them. Even the most well-conceived improvements programs fall flat if teachers lack the skills to implement them. Teachers must bring the principles of the learning community to life in their individual classrooms. (DuFour \& Eaker, 1998, p. 206) 
Teachers must be willing to take risks and participate in planned activities to bring the staff together. Teachers must be open to learning and implementing new instructional strategies. The traditional form of teaching with conformity to rules and teaching to standards must be changed to a more open and adaptive form of teaching and learning. Teachers working on teams develop a common instructional framework that guides the curriculum with related assessment for each grade level (Newmann et al., 2001). Teachers work together to analyze student assessment data to provide continuous improvements in the instructional and learning process. Without a doubt, "teachers represent the heartbeat of a school, and the changes essential to school improvement must be manifested by individual teachers at the classroom level. It is impossible to create good schools without good teachers..." (DuFour \& Eaker, 1998, p. 233).

Another key participant in the learning community is the student. Baker (1996) compares the role of the student to that of an apprentice who learns through active participation.

Numerous research studies (Sarason, 1991; Goodlad, 1984) that have observed closely the work of students in the classroom report the same conclusion: During the school day, most students are passive recipients of teacher-directed activities. This passivity often leads to boredom, which, in turn, sometimes creates distractive behavior... Teachers cope with distractions by increasing their control over all the students. The unproductive cycle of teacher control and student passivity must be broken by new opportunities for active involvement in intrinsically interesting pursuits. (p. 5)

Likewise, parents are important partners in the learning communities. No longer should parents be regarded as external spectators to the classroom. "While there is an abundance of research establishing the fact that parents' involvement in the education of their children is highly desirable, parents and educators continue to struggle in their 
efforts to define exactly what that role should be" (DuFour \& Eaker, 1998, p. 252). Baker (1996) believes that parents are significant educational partners: "Principles of guided participation require extensive involvement of parents in every phase of their child's educational experience" (p. 5). Parents are the first teacher a child knows when he/she comes into this world and should continue to serve this role in a child's education. Parents are also learners in the learning community. Parents, along with teachers and administrators, must work together to develop meaningful learning experiences for students.

In conclusion, building learning communities is the work of school leaders and teachers. Building learning communities is not an easy task and requires strategic planning and guided participation for all key players (Baker, 1996). Senge (1990) believes that "Learning organizations represent a potentially significant evolution of organization culture. So it should come as no surprise that learning organizations will remain a distant vision until the leadership capabilities they demand are developed" (p. 22). Baker (1996) contends that "Principals and teachers hold the keys to getting thing started. Their initiatives must reach out to parents and other adults who also dream of new ways to make schools exciting places of mindful engagement" (p. 6). 


\section{CHAPTER III}

\section{METHODOLOGY}

\section{Statement of the Problem}

Many urban schools are failing the students they are expected to serve, while other schools in similar urban settings are excelling. For the past quarter century researchers have examined various effective school correlates that result in high student performance. These correlates are considered to be important and are frequently incorporated in state mandates and district policies. But adoption of these correlates is only the first step to academic success. Other indigenous factors, such as relational trust and instructional program coherence, must also be considered in any account of sustained high quality school performance. This study examines a high performing school according to the five themes of the National Center for Education Accountability (NCEA) Best Practices Framework and organizational properties of relational trust and instructional program coherence. This study also examines contextual factors that contribute to a professional learning community that supports the Best Practices Framework, relational trust, and instructional program coherence.

\section{Background of the Study}

In this era of school failure and barrage of public criticism of schools, the purpose of this qualitative case study was to analyze a high performing school serving large minority and low socioeconomic student population. The study identifies indigenous 
factors and practices that contribute to the success of the school. The foundation of this study began with the analysis of the large body of effective schools research, which began decades ago as many of the same issues surrounding poor student performance continue to be faced today. This study is an extension of a much larger study initiated by the National Center for Education Accountability (NCEA), which sought to identify consistently high-performing schools across the United States and to investigate what practices worked well in those schools. Illinois State University was chosen as a partner in this large study of Best Practices, which began in 2001. This study was conducted under the supervision of the Illinois State University research team.

This chapter will include the statement of the problem, background of the study, research design, research questions, phase I: site selection, phase II: sample population, methods, data collection and phase III: analysis, protection of human subjects, and a summary.

\section{Research Questions}

The following questions established the conceptual framework and thus guided this study:

1. To what extent are the five themes of the NCEA Best Practice Framework developed in the high performing school?

2. To what extent is Relational Trust developed in the high performing school?

3. To what extent is instructional program coherence developed in the high performing school?

4. What is the influence of the principal's leadership style on the staff and school climate?

5. How do the five themes of the Illinois Best Practice Framework, instructional program coherence, and relational trust contribute in creating a professional learning community? 


\section{Research Design}

As part of a national research study to analyze exemplary schools using the National Center for Educational Accountability Best Practices Framework (Appendix B), this study continued with the qualitative approach used in the larger study. Specifically, this study utilized a qualitative case study approach. Merriam (1998) described the important aspects of qualitative research as "the goal of eliciting understanding and meaning, the researcher as primary instrument of data collection and an inductive orientation of analysis, the use of fieldwork, and findings that are richly descriptive" (p. 11). Merriam (1998) contends: "A case study design is employed to gain an in-depth understanding of the situation and meaning for those involved" (p. 19). A case study method was employed for this study, as it allowed for the in-depth study of one school and enabled the researcher to identify and analyze the indigenous practices that make an urban school effective despite high poverty levels and a significant minority population. As an extension of the larger study, this researcher went further with field notes, observations, interviews, a survey of teachers, the collection of artifacts and extensive narrative data over an extended period of time to gain a more comprehensive understanding of the context of which the five best practice themes are part of the school's organizational development. The research design sought to examine a high performing school in accordance with the five themes (Curriculum; Staffing; Instruction; Monitoring Student Progress; and Recognition, Rewards \& Intervention) identified by the National Center for Educational Accountability Best Practices Framework (NCEA) and to examine the existence of instructional program coherence, relational trust and leadership style. The 
research involved one high performing urban school site and utilized observation, interviews, and survey instruments to document the school's indigenous practices.

The study was conducted in three phases. Phase I involved the original study conducted by the Illinois State University team. The team conducted the site selection and a complete exploration of the district and school. Phase II of the study centered on this researcher's study of the school's policies, curriculum, instructional practices, personnel, and related artifacts. Phase III of the study involved a detailed analysis of interview data, artifacts, and field notes.

\section{Phase I}

In Phase I of the study, the Illinois State University team initiated the original National Center for Educational Accountability (NCEA) Best Practice study in Illinois. This researcher joined the Illinois State University research team to participate in this original study and to launch an extension of the study. The study began with a rigorous site selection process.

\section{Site Selection}

The Illinois State University team (Curry, Baker, \& Pacha, 2007) conducted the site selection process choosing this particular school from the statewide sample for the national study. The Illinois State University Best Practices research team selected the school based on rigorous selection criterion that formed the foundation of this research methodology. According to the research team (Curry, Pacha, \& Baker, 2007), the school was selected based on a regression analysis of school performance over a 3-year period relative to demographically similar schools. The criteria used involved standardized achievement test data over a 3 -year span, a minimum poverty level of $20 \%$, and student 
distributions of race/ethnicity and English Language Learners with attention to the percent of students tested, and an examination of potential anomalies in state data (Curry, Pacha, \& Baker, 2007). Based on the criteria described above, a statewide sample of high performing schools was identified. The school selected for this case study was one of 10 schools in the statewide study.

With the study site secured, the Illinois State University research team scheduled interviews and observations at the district and school levels. Specifically, the team conducted interviews with the district superintendent, the assistant superintendent, principal, counselor, librarian, disciplinarian, and various groups of teachers. The NCEA interview protocol was used to conduct all interviews (Appendix A). The team observed school staff meetings, classrooms, and the school's morning entry and dismissal procedures. According to scholarly research techniques, "Opportunity should be taken early to get acquainted with the people, the spaces, the schedules, and the problems of the case" (Stake, 1995, p. 54). During the original study, this researcher was afforded the opportunity to observe at the school level and to engage in numerous informal conversations with the superintendent, principal, counselor, librarian, disciplinarian, and some teachers. As a result of participation in the original study, this researcher gained first-hand knowledge of the school, its people, and valuable research data to begin further analysis for the extension study.

\section{Phase II}

In Phase II of the study, this researcher initiated the extension of the original study, which involved extensive fieldwork at the school site. "Fieldwork is the central activity of qualitative inquiry. Going into the field to conduct qualitative inquiry means 
having direct and personal contact with people under study in their own environments" (Patton, 2002, p. 48). In the quest to gain an understanding of the uniqueness of this school, this researcher made 16 visits to the school site during the spring of 2006. According to Bryant (2004), "Qualitative studies that utilize multiple data sources typically prove more persuasive than studies that do not" (p. 106). In this study, the entire school setting was explored using various techniques, which resulted in the collection of multiple forms of data, observation, interviews, surveys, and artifacts.

Person-to-person interviews were an integral part of the fieldwork conducted in this study. Merriam (1998) suggested interviews are likely the most commonly used form of data collection in qualitative research in education. This researcher conducted nine person-to-person interviews that included the principal, disciplinarian, counselor, and six teachers using a structured interview protocol. Glesne (1999) contends "an hour of steady talk is generally an appropriate length before diminishing returns set in for both parties" (p. 78). In keeping with this research standard, all interviews were approximately 45 to 60 minutes in length. The interviews were semi-structured using Instructional Program Coherence protocol adopted from the education research work of Newmann et al. (2001) to evaluate the existence of Instructional Program Coherence in the school. The interviews were audiotape recorded to ensure accuracy and preservation for analysis.

Surveys are yet another method of collecting relevant data. This study also employed the use of a Relational Trust Survey adopted from the educational research studies of Anthony Bryk et al. (2002). The Relational Trust Survey was utilized to evaluate the schools organizational structure. Fourteen teachers completed the Relational 
Trust survey instruments (Appendix D). The surveys were left on the mail counter in the office for teachers to take them and returned to a sealed box in the library. This measure was taken to ensure the confidentiality of participants and their comments. Participation was strictly on a volunteer basis.

Observations were a large part of the fieldwork conducted in this study. "The researcher must physically go to the people, setting, situation, site, institution (the field) in order to observe behavior in its natural setting" (Merriam, 1998, p. 7). During the 16 visits made to this school, this researcher conducted observations throughout the entire school. Every classroom in the school was visited, including physical education, library, and computer classes. This researcher also attended school events: Black History Program, Talent Show, Market Day, Awards Programs, and Parent-Teacher Conference Day. Field notes were taken during all observations.

As stated by Le Compte and Preissle (1993), "The resulting artifacts constitute data indicating people's sensations, experiences, and knowledge and which connote opinions, values, and feelings...they are material manifestations of cultural beliefs and behaviors" (p. 216). In an effort to study the school in-depth, this researcher collected a vast array of artifacts, such as a mission and vision statement, policy statements, curriculum guides for reading, mathematics and science, lesson plans, staff meeting agendas, professional development protocol, master schedules, and supplemental reading instructional materials. These artifacts were collected and analyzed as they related to the school's instructional operations or organizational development. In addition, many informal conversations occurred with teachers and other staff members at this school site and are reflected in the field notes. 


\section{Description of the Sample}

The sample population consisted of the school personnel who chose to participate. The school principal, disciplinarian, counselor, 6 teachers participated in person-toperson interviews, and 14 teachers completed surveys.

Participants were recruited at the school site via a letter describing the study and a signed Consent to Participate Form (Appendix C). The study description letters and Consent to Participate Forms were circulated at the school site during a staff meeting. This researcher was allowed to introduce the study and distribute the study description letter and Consent to Participate Forms during the staff meeting. Participation was strictly on a volunteer basis only, and there was no rewards or penalties for participation or nonparticipation.

\section{Protection of Human Subjects}

Participation in the study was strictly on a voluntary basis and limited to school personnel. There were no physical, psychological, or social risks involved for participants. Participants were made aware that there was no penalty for nonparticipation. Participants were provided an overview of the study and required to complete and sign an informed consent before participating in the study. Participants had the right to decline participation at any time during the study without any retribution. Participant anonymity and confidentiality was protected by not including actual names with what was said. All observation notes, interview notes, audiotapes, and artifacts were kept in a locked file cabinet at the researcher's residence. This researcher maintained sole access to the data collected for this dissertation study. All data listed above was destroyed upon the completion of this dissertation study by the co-researcher. 


\section{Analysis of Data}

\section{Phase III}

In Phase III of this study, the researcher began the analysis of the data. Phase III involved searching for a deeper understanding of the instructional and organizational practices at this school through the analysis of the multiple data collected during Phase II of the study. The data included field notes, interview data, survey data, and artifacts.

The analysis began with transcribing the audiotapes of the interviews and field notes. Next, this researcher examined transcript data and decided upon the qualitative research coding technique to use for data analysis. With the research questions and the NCEA Best Practice Framework as guides, the transcript data was categorized in reference to these relevant guiding points. In this method of data analysis "the researcher seeks a collection of instances from the data, hoping that issue-relevant meaning will emerge" (Creswell, 1998, p. 154). Stake (1995) contends that categorizing is a most common as well as essential part of the analytical process.

The search for meaning often is a search for patterns, for consistency, within certain conditions, which we call 'correspondence... We can look for patterns immediately while we are reviewing documents, observing, or interviewing-or we can code the records, aggregate frequencies, and find patterns that way. Or both. (p. 78)

As the coding and categorizing of the data progressed, this researcher developed a graphic organizer in the format of a large matrix to further organize the data and provide a visual aide to work from. This researcher analyzed the documents and documented the emerging patterns.

Next, this researcher decided upon using two rubrics to analyze data from interview responses and from the survey instrument. First, the Instructional Program 
Coherence Rubric (Newmann et al., 2001) was used to evaluate the existence of instructional program coherence in the school based on participant responses to interview questions. The responses were then applied to the rubric based on four levels of possible responses. The responses were evaluated to describe the existence and strength of the instructional program coherence found in the school.

The next rubric, the Relational Trust Rubric (Bryk et al., 2002), was used to evaluate and describe the Relational Trust at this school. This rubric had four levels of possible responses for each survey question. The researcher tallied all responses to describe the percentage of participant responses in reference to Relational Trust in the school.

Finally, this researcher examined the artifacts that were collected at the school site and synthesized this information with the entire data set. After this exercise, conclusions were formulated from all existing data reviewed and analyzed.

\section{Summary}

This chapter presented the researcher's methods used to conduct this qualitative case study of an exemplary urban school serving an at risk student population. The study was designed to examine the indigenous practices of the school to glean factors that contribute to the school's success. The study also examined the school's culture in terms of relational trust and its impact on the working conditions, instructional program coherence and the leadership style.

The study was conducted in three phases. Phase I began with the selection of the high performing urban school site to be studied. With permission granted by school officials, the study officially started with an all staff meeting where the project was 
introduced and correspondence distributed. Phase II involved school site observations, group and individual interviews, and the collection of documents and artifacts. Armed with a great amount of data to process, the researcher began phase III of the study. The researcher transcribed audiotapes, typed field notes, and examined documents and artifacts. The researcher reviewed, analyzed, and coded all data in accordance to qualitative standards in order to identify those indigenous practices that impact the success of the school. Chapter IV will reveal in detail what the researcher discovered about the school site. 


\section{CHAPTER IV}

\section{RESULTS}

This research study sought to examine the practices and unique characteristics of a high performing school based on the five themes of the "Illinois Best Practice Framework" which are adapted by the National Center for Educational Accountability's (NCEA). The five themes of the Illinois Best Practice Framework address: (a) curriculum and academic goals, (b) staff selection, leadership and capacity building, (c) instructional programs and practices, (d) monitoring and analysis of data, and (e) recognition and intervention. This study also examined the organizational properties of relational trust and instructional program coherence that contribute to a professional learning community.

The data and artifacts for this study were acquired through several school visits over the course of a 4-month period. The co-investigator conducted interviews with the principal, teachers, and teacher teams. School visits included extensive observations throughout the school day that included classrooms, hallways, lunchroom, library, and various school improvement meetings. Further, a variety of school documents were collected and analyzed as a part of this study. Themes that emerge from this study were grounded in numerous observations and recurrent comments from several staff members. Chapter IV contains the following three sections:

1. A narrative profile of Robinson Junior High School (pseudonym), the study site. 
2. The findings of the five research questions that guided this study.

3. A summary of emerging findings resulting from the study.

\section{School Profile}

Robinson Junior High School (RJHS), the study site, is located in a suburb of a large metropolitan urban city. The school is part of a K-8 district that serves 10 schools from 4 small communities.

This modest working class community received thousands of low-income families over the years from the nearby large metropolitan urban city. Families come to this area seeking a better life and education for their children. Robinson Junior High School is nestled in a predominately black community. The homes are small to medium singlefamily dwellings that range from well to poorly kept. Sidewalks are cracked, separated, and uneven, making walking difficult. As one approaches Robinson Junior High School, the large modest-looking two-level brown brick building with a very poorly maintained parking lot seems barren. A large fenced-in field located on the south of the campus serves as the sports and physical education area for the school. There is no garden, shrubbery, or decorative touches on the school grounds. There is no school marquee. Though visibly deteriorated, the school grounds are kept clean and free of debris. Robinson Junior High School's outside is not nearly as inviting as what one finds inside.

Robinson Junior High School serves seventh and eighth grade students and shares the building with the elementary school. Both schools share the gym, teachers lounge area, and sports field. The cafeteria is used solely by the elementary school, as RJHS staff elected for students to eat in their homerooms. Visitors must ring a doorbell and wait for admittance by the office clerk who activates the buzzer that unlocks the door. 
Upon entering the building, all visitors must check in at the office located next to the entrance. The staff is friendly and eager to assist. As one walks down the hallways, one sees bulletin boards decorated with student pictures, work, and decorative flowers and borders. The hallways are quiet and orderly. Depending on the time of day, students may be walking in line to another classroom, standing in line for washroom time, or at their lockers. During class time, hallways are usually quiet except for the voices of teachers or students in classrooms engaged in a lesson. During class time one will frequently see the principal or the dean of students casually monitoring classrooms and any student movement in the hallways.

Robinson Junior High School (RJHS) has a strategic student discipline policy that encompasses not only behavior, but includes attire, attendance, and academic progress. There is also a reward system component. The uniform policy stipulates that male students must wear navy blue trousers and white shirts with belts and shirts tucked in. Female students are required to wear navy blue skirts or pants with white blouses; white tee shirts are not acceptable for anyone. The dress code policy, though strictly enforced, is widely supported by the district, parents, and teachers. In fact, most teachers and the principal wear the student uniform colors, although it is not required for them. Student behavior is another important part of the discipline policy at RJHS. The Dean of students monitors student behavior infractions by offender, type of infraction, and frequency. The Dean of students renders a discipline report at the weekly faculty meeting and offers suggestions to eliminate possibilities for infractions to occur. Teachers are very receptive to the discipline policy and work without pay to help enforce it. Teachers volunteer to facilitate Saturday and after school detentions, even though there is no funding in the 
school budget to pay them. Students receive detentions for excessive tardiness, absenteeism, and other acts of misconduct. The reward component involves dress down days and quarterly school-sponsored trips for students who did not commit infractions and maintained acceptable academic progress. Overall, this student discipline policy has proven to be a great motivating factor in student progress at RJHS.

Illinois State Board of Education (ISBE) Demographic Data for the 2005-2006 school year identified a student population of 481 . ISBE data indicated the student population to be $98.1 \%$ Black, $0.2 \%$ White, $0.4 \%$ Hispanic, and $1.2 \%$ Multi racial. The school has a student population that is $84.2 \%$ low-income with $21.4 \%$ mobility rate. The school has a student attendance rate of $94.3 \%$ with a $0.0 \%$ Truancy rate. Over $40 \%$ of the students come from foster homes. The average class size ranges from 22.2 students for seventh grade and 24.1 for eighth grade. ISBE indicates parental contact at $96.4 \%$. As indicated by ISBE, all teachers are highly qualified.

Robinson Junior High School's day starts at 8:25 A.M. for teachers and 9:00 A.M. for students. The school day ends at 2:45 P.M. for both students and teachers. The school has 10 seventh grade classrooms and teachers, 10 eighth grade classrooms and teachers, 2 special education teachers, 15 ancillary staff, and 4 support staff. There are two self-contained special education classrooms. RJHS has a coherent staff facilitated by a very committed core group of long standing teachers who serve as mentors to new teachers and staff. Teacher leaders in the school have a self-conscious awareness of their responsibilities to improve and sustain programs. The school follows a modified block schedule whereby students are with the homeroom teacher for the first half of the school day then, after lunch, students go to the partner teacher for the second part of the day. 
Homeroom teachers are either reading or math endorsed. Teachers endorsed in reading teach the language arts subjects and social studies. Teachers endorsed in mathematics teach math and science classes. Students are escorted to ancillary classes for instruction in library science, computer science, art, health and physical education. The school did not have a music program but did afford interested students the opportunity to participate in a school choir offered after school.

\section{Research Question Findings}

\section{Research Question 1}

To what extent are the five themes of the NCEA Model developed in high performing Schools?

Theme 1: Curriculum and academic goals. Theme one addresses:

Curriculum and Academic Goals: Practices in this theme enable high performing school systems to establish clear, specific academic goals that apply to all students in every grade of their education. All educators agree upon these learning goals and are held accountable for enabling each child to reach them. (Luce, 2005, p. 67)

A school's curriculum is a broad scope of concepts and skills that students are to learn in each subject area at each specific grade level. Robinson Junior High School's curriculum starts with the Illinois Learning Standards. The local district engaged the services of the South Cook County Intermediate Service Center to provide trainers and consultants to assist district administrators and teachers in aligning their curriculum according to mandates defined by the State of Illinois Learning Standards. As a result, RJHS has a detailed set of Curriculum Coordination and Alignment guides that includes Illinois Learning Standards, Benchmarks, Performance Descriptors and assessment criteria for each grade level in the subject areas of Reading and Mathematics. These Curriculum Coordination and Alignment guides are also aligned to the textbooks currently being 
utilized by the school. In fact, teachers have been trained how to align new textbooks to the curriculum guides, design lesson plans, and conduct regular assessment. One veteran teacher leader commented,

One thing that we do here is we take the state standards and we align our curriculum towards the state standards. So we actually sit down, look at the state standards to see what needs to be taught and we align our curriculum that way.

The curriculum guides are revisited yearly for revisions as the school strives to make their curriculum more ISAT focused. These detailed curriculum guides leave nothing to chance, but lay out a specific set of Illinois Learning Standards, related skills and the sections of the textbook where the concepts are covered each day. For example, Illinois Learning Goal 1A states "Students who meet the standard can apply word analysis and vocabulary skills to comprehend selections." It is important to note that this Learning Goal is the same for all elementary grade levels and only the performance descriptors differs as the performance becomes more complex as the grade level increases. The Stage G seventh grade Performance Descriptor states, "Use prefixes, suffixes, and root words to understand word meanings." The Houghton Mifflin Spelling and Vocabulary textbook units $2,3,8,9,14,15,27$, and 32 are cited for instruction, student practice, and suggested assessment. Teachers as well as administration hold each other accountable to follow a timeline of instruction and assessment as indicated by the curricular guides.

Student assessment at RJHS is strategically planned and methodical in nature. The district has purchased Ed Visions diagnostic testing software. At the start of each new school year, RJHS administers the Ed Visions test to all students. The Ed Visions test is also administered at the end of the school year. Teachers are trained to use the test data to identify students' strengths, weaknesses, gains or losses in reading and mathematics. 
This becomes a powerful tool for teachers and administrators when planning school improvement, student organization, and lesson plans or revising curriculum. One teacher commented, "We begin the school year with the Ed Visions Assessment and every student is tested. I like the assessment because it identifies students'strengths and weaknesses." When asked about common assessment at RJHS a teacher leader commented, "When you talk about assessment in common there are the Ed Visions Tests and the ISAT; these are tests that we use to inform our decision making. Weekly assessment is where we show our individuality." Weekly assessments at RJHS are not always common among grade levels, because some teachers choose to create their own tests based on what they actually taught even though grade levels use the same textbooks and instructional materials. One veteran teacher stated:

I teach based on the ISAT and some parts of the chapter I may skip; however, it may be covered on the publisher's chapter test so I do not use the publisher test. It is not fair to students to include things on a test that were not covered so I create my own tests based on what I taught.

Yet another teacher (second year) commented:

I use publisher tests and authentic tests. I am still reflecting and thinking of ways that I can assess student learning better because some students just do not test well on paper pencil tests. I am looking for different assessment strategies that I can use. Most veteran math teachers here use modified publisher tests and authentic testing along with differentiated instruction.

Teachers explained that some of the textbooks series used at RJHS offer assessment software. This software enabled teachers to create their own assessment based on the concepts taught. Teacher interviews revealed that most teachers preferred this type of weekly assessment instead of publisher-created assessment.

Another important factor influencing school success is a coherent staff. This factor is evident at RJHS through a great spirit of teamwork. In fact, the principal 
believes very strongly in the concept of teaming. To this end, RJHS has several teacher teams: grade level, curriculum, school improvement, social committee, and leadership team, all with designated meeting times. For example, the curriculum teams have a designated teacher-leader who attends a series of curriculum district wide workshops at District Office and, in turn, presents the information that will result in increased student achievement. A math teacher commented: "Our math-science team leader attends the district level meetings where she is able to voice what students are expected to know and be able to do when entering Robinson Junior High School." The district level curriculum meetings afford receiving schools the opportunity to collaborate with feeder schools about curriculum and learning expectations. According to the interviews, all teachers expressed support for curriculum leaders. A teacher commented, "We discuss what is working or not working and what trends we are seeing. We always collaborate. When someone needs help, others are there to help; you just have to ask." Another teacher commented: "Vertical seventh and eighth grade level discussions happen regularly at our math-science meetings so seventh graders cover what they need before entering eighth grade." Through these curriculum meetings, teachers at RJHS are able to hold each other accountable to cover the aligned curriculum to continue student achievement at each grade level.

Theme 2: Staff selection, leadership, and capacity building. "These practices facilitate the selection and development of high-quality teachers and instructional leaders, including district leadership, school principals, and teacher leaders" (Luce, 2005, p. 67). High performing schools do not occur accidentally. They occur because competent people are recruited to manage and rally stakeholders to work together for the common 
good of the organization. This strategy is evident at Robinson Junior High School. They have established procedures for the recruitment and retention of highly qualified staff. The framework for these successful recruitment practices begin at the District Office with the process of advertising, screening, and hiring guidelines that help select the best candidates to deliver quality instruction and build cohesive schools.

The District Superintendent leads the search committee for a new principal. The Superintendent revealed the district's preference to promote from within the system, however, noting that the district always followed procedural guidelines to advertise externally as well. The Superintendent referred to this practice as administrators being "home grown." The Superintendent admitted that all the current principals in the district were former teachers from within the district. The Superintendent works with the school to form a committee of teachers and staff who will recruit and screen candidates for the principal position. Robinson Junior High School teachers, under the direction of the Superintendent, formed this type of committee to select the current principal who was formerly a classroom teacher there. The recruitment committee established key expectations for the position and composed a series of questions to pose to the candidates during interviews. Teachers at RJHS were concerned about improving student discipline and sustaining a major grant funded school improvement program that had been implemented. The success of this innovation becomes a key expectation for principal candidates. In the final scheme, the Superintendent and committee members have the authority to make one recommendation to the school board for final approval. The teachers at RJHS really believed in their teacher colleague as their new principal. After detailed deliberations with the school board, she was selected. 
Teacher and non-professional staff selection starts at the district office as well. The District Office retains a file of qualified candidate information. The candidate information is presented per a principal's request for review and consideration. At RJHS, the principal prefers a team approach to staff selection, so a team of teachers is formed based on grade level and subject. The search team meets to develop criteria and expectations. Next, a series of questions are developed to pose to the candidates during the interview process. The candidate interview process is also a team approach. The principal chooses the best candidate with the consideration of the search team's recommendations. The principal informs the superintendent of the search committee's candidate selection. This collegial approach to staff selection offers promise of adding new recruits who are compatible with the incumbent staff and able to become viable team players in the professional learning community.

Recruiting good people to work is just the first step of many in a successful school. The next step is providing support with mentors who help new principals and teachers acclimate to the school's culture and professional development trainings to move forward with successful careers. The school district in this study is especially active in this support and mentor process. Since it is a relatively small school district, the Superintendent mentors and consults regularly with the new principals. The district is also active in the mentoring of new teachers.

New teachers are assigned two mentors: (a) a district level mentor who helps the teacher to understand district policies, practices, and expectations, and (b) a trained teacher mentor who provides continuous coaching and support for the first 2 years. At Robinson Junior High School, the principal also plays the role as mentor to new teachers. 
The principal meets with the new teacher starting in the summer before the start of the school year and during the first semester of the school year. The principal realizes the importance of mentoring new teachers. The principal commented that:

I went through a lot of mentor training and I know it is very important. And as a principal, when the teachers come in before school starts, I like to have my teachers hired by the end of July. So then, at least, by the first of August, I can have them come into the building and I can go over the expectations with them and talk about how they need to work with the curriculum because I know they will struggle with that, classroom management, and discipline. During the first few months I really, focus on going into the school and giving a lot of myself to the teachers.

The Dean of students also supports new teachers as directed by the principal. He makes frequent short walk-through observations of the classroom to ensure classroom management and discipline are under control. He gives the new teacher feedback, assists with any problems, and keeps the principal informed.

"The principal recognizes the need to support new teachers, but she also knows her duties as principal require sound judgments about teacher performance. She must balance these two contradictory responsibilities" (Pacha, Gyenfie, \& Baker, 2006, p. 8). Starting in the summer and through the fall, the principal mentors and supports her new staff members, but by the middle of the year her obligations shift to that of supervisor and thus conducting official performance evaluations. Ultimately, the principal must make the tough decisions on retaining the new teacher or informing the person that he or she will not be returning in the fall. One of her colleagues commented on the principal's compassion and skill in this important role,

The principal is always straight with you. If you are doing something wrong after she has given you information and strategies to use, and you do it on your own and it does not work, she will pull you into her office and redirect you but she is very professional about it. Even though she was a friend earlier, she is still the 
principal, and you always know where she is at or where she is coming from. So by February or March, you really have an idea if you are coming back or not.

This system of support described above from the principal to mentors and teacher partners is re-enacted with every new teacher to the school. Once the principal has made the decision to retain the new teacher for the upcoming school year, the mentor and teacher partner will then begin to prepare the new teacher for the summer teacher planning activities. It is apparent that the principal understands the tough work of being a school leader as she commented, "It is very hard to be a mentor and an administrator."

The work conditions of teacher isolation as observed and written about by many prominent educational researchers is not an option at Robinson Junior High School. Social arrangements for teachers to work collaboratively are pervasive throughout the entire school system. Six formal systems are firmly in place that afford teachers opportunities to share ideas. First, the District has set up a training program for teacherleaders who have been identified by their principals as exceptional classroom teachers. These teacher-leaders meet at the District office twice a month (Monday evenings for 2-3 hours) to work on curriculum, assessment, and instructional strategies. Teacher-leaders are expected go back to their schools and share the new resources with their colleagues. They are also expected to apply the information and new strategies in their own classrooms. RJHS has three designated teacher-leaders in the fields of reading, math/science, and technology.

Second, all teachers are paired with a teacher-partner, and each day they are given the opportunity to work together from 8:25 to 8:55 A.M. The teacher-partners also work together in conducting parent-teacher conferences throughout the school year. The 
teacher-partners teach the same grade level and service the same group of students. One teaches the math and science and the other language arts and social science. This partnership arrangement helps teachers in countless ways ranging from identification of students' strengths, weaknesses or behavior issues, daily planning, the sharing of successful instructional strategies and so many more. I observed a teacher-partner working with a substitute teacher who was replacing a colleague for the day. It is most certainly an all-win arrangement for teachers, students, and administrators.

Third, another opportunity for teachers to come together is the faculty meeting held every Thursday morning starting at 8:00 A.M. Although this meeting is outside the teachers' contractual agreement time schedule, most teachers (approximately 80\%) attend. The $20 \%$ who do not make the meeting on time simply rely on colleagues for the information. I observed teacher-partners collecting meeting agendas and other handouts for colleagues who were absent. This staff is considerate and supportive of each other. The principal commented:

If teachers are having a rough day we are here for each other. We help each other by listening, caring, sharing, and if a teacher needs to take a break we cover his/her room for them. We support one another and assist each other in different situations.

This observable camaraderie and teamwork definitely makes everything within RJHS work better.

Fourth, subject area meetings are yet another opportunity for teachers to work together. In the subject area meetings, teachers of all grade levels come together under a specific subject area such as language arts, math, science, or technology. Subject area meetings afford teachers time to share new instructional strategies gleaned from district- 
sponsored professional development and/or a teacher's individual professional development. In fact, the school has a policy governing individual professional development as stated by a teacher, "You just can't go to any workshop because it seems interesting.... We must state how the workshop relates to school improvement goals and how we will use it in our classroom to help students." The teacher went on to say, "It is guaranteed that if you go to a workshop, you will have to present it to the team." In subject area meetings teachers also analyze assessment data, alignment topics, review new textbooks, and ask their colleagues for help as needed. In fact, "if teachers are having a problem, they can also go to the principal. She will make time and put another teacher in the classroom so you can observe that lesson or concept." Another teacher commented, "We all use our strengths in different ways, however; when someone needs help or ideas I find that other teachers are more than willing to share ideas, resources and suggestions." A teacher-leader commented:

I think subject area teams are one of the best things that the principal set up. Math teachers from both seventh and eighth grades meet regularly. The eighth grade teachers have stated to the seventh grade teachers that 'this is what we need you to cover these concepts well so that students who are coming to eighth grade are ready to do eighth grade work.

This vertical sharing allows teachers to narrow the scope of concepts and focus more on prerequisite concepts knowing that students will cover other concepts in the next year.

Fifth, teachers meet by grade levels to review and address concerns that are specific to seventh or eighth grade students. In these meetings teachers plan student field trips, assemblies, standardized test practice activities, and other student activities. Teachers also use these meetings to seek help from colleagues, share ideas gleaned from workshops, and discuss what is working or not working. 
Finally, the curriculum development meetings are held twice monthly, every other Friday at 8:00 A.M. This team also meets during the summer to work on curriculum. Teachers are not required to attend this meeting, although most teachers do attend. This team is constantly analyzing Illinois Learning Standards, the school's curriculum, and assessment data to inform their Instructional Program and Practices.

Theme 3: Instructional programs, practices, and arrangements. "Practices in the third theme concern the provision of tools — such as instructional materials, adequate instructional time, and technology — that enable educators to reach the academic goals set by the district" (Luce, 2005, p. 69). The educators at RJHS have three interrelated instructional program components that work together to create a learning community whereby students are progressing: (a) a strategic student discipline program, (b) a multilayered academic program infused with technology, and (c) a school-wide modified block schedule.

First, the strategic student discipline program, as discussed earlier in this chapter, creates a safe and healthy environment for students and teachers. Upon entering RJHS, both students and teachers are trained and/or refreshed in the terms and responsibilities as articulated in the discipline program. The student discipline program addresses all expectations of student life from attire, attendance, and behavior to academic progress, with consequences and rewards all spelled out. This student discipline program is widely known throughout the school and both students and teachers are held accountable to comply with it. "Like all effective student discipline programs it begins with all adults (principal, dean of students, teachers, parents) sharing common responsibilities for the daily conduct of the students" (Pacha, Gyenfie, \& Baker, 2006, p. 11). 
The Dean of Students has major responsibility for overseeing and monitoring the student discipline program at RJHS. The Dean of Students makes weekly progress reports about discipline and related concerns at the weekly faculty meetings. These reports track and tally student infractions, consequences, identify faculty inconsistencies of compliance, and offers suggestions for improvements. Based on these reports, and before school-sponsored trips or incentive programs take place, teachers are given a list of students who are not able to participate.

The discipline program at RJHS is a highly reliability system that works, because there is shared leadership among administrators and teachers who maintain consistency in their expectations, communicate effectively to all parties inside the school and the home, and administer the rules with transparency and a sense of fairness. (Pacha, Gyenfie, \& Baker, 2006, p. 11)

This type of teamwork in the enforcement and monitoring of the student discipline program creates an environment where students are safe and are motivated to conduct themselves in an orderly manner. In fact, students enjoy coming to school and many participate in extracurricular activities held after normal school hours. Some students even hang around in the gym just to socialize after school knowing they are in a safe environment. This strategic student discipline program at RJHS allows both teachers and students the opportunity to focus on their academics without the distraction of disciplinary occurrences. Undoubtedly, a good student discipline program is a major influencing factor in effective schools.

Second, RJHS uses a multi-layered academic program that starts with the Illinois Learning Standards based curriculum. The textbooks and instructional materials are purchased from widely known book publishers. These textbook publishers are the ones commonly used by most schools across Illinois. This first layer of the academic program 
is basic standard operating procedures practiced by most schools. However routine, instructional practices of previous years have been strategically modified at RJHS. The staff at RJHS all agreed that school improvement and intervention efforts were sorely needed. Accordingly, RJHS administrators and teachers recognized that the school needed to have an academic program that would meet the learning needs of low-income students and afford them academic success. Hence, 7 years ago RJHS staff began their quest to address the school's academic challenges. First, they chose reading improvement as their most needed improvement and made this their number one priority. Next, they acquired a 3-year grant for the services of the Center for Research on Learning from the University of Kansas. Hence, the school embarked on training in the Strategies Instruction Model.

"All teachers were trained in a mastery learning approach designed for students typically classified as low achievers, underachievers, culturally different, or learning disabled" (Pacha, Gyenfie, Baker, 2006, p. 12). The Strategies Instruction Model consists of three instructional strands: (a) the Acquisition Strand, which addresses skills such as word identification, paraphrasing, self-questioning visual imagery, interpreting visual aids, and multi-pass; (b) the Storage Strand, which addresses skills in first-letter mnemonic, paired associates, LINCS vocabulary, listening and note taking; and (c) the Expression and Demonstration of Competence Strand, which addresses skills in writing sentences, paragraphs, error monitoring, themes, assignment completion, and test taking. The school-wide reading textbook series is used in conjunction with the Strategies Instruction Model. All teachers, no matter what their subject area endorsements may be, are trained to lead or assist in the daily lessons. Ancillary teachers are assigned to 
classrooms to assist. All teachers are assigned a binder of preplanned or preformatted lessons to be taught daily. It is known by all staff that there are no deviations from the prescribed format or timeline. When a teacher is absent, another RJHS teacher will oversee that lesson for the period. These lessons are taught school wide during the first period of every school day without failure. Initially, many teachers struggled with this new program and some teachers even questioned why they had to teach reading at all. However, after student achievement began to show marked improvement and teachers got more experience in the program, teachers began to appreciate and support the program.

This heightened support eventually led to total staff buy-in to the program; hence, the program has been sustained for 4 years and continues beyond the time of grant support. Now, widely accepted and valued, the program has been renamed RAMS (Readers Achieve More Success). This clever new name was most appropriate, since the RJHS mascot is a ram and the motto states "Home of the Rams." After the reading success, the school tried to duplicate the RAMS program for mathematics. RJHS math department has developed a binder that focuses on math skills and concepts but utilizes the same mastery learning strategies and techniques.

Another layer in RJHS's academic program is the Accelerated Reader Program. The Accelerated Reading Program is a computerized reading information system with thousands of authentic literature-based books and computer-based quizzes. The quizzes assess students' progress in reading comprehension and vocabulary. This program affords students the opportunity for personalized reading practice with quick feedback. At RJHS, the librarian facilitates the program. The library houses thousands of books 
that are among the software titles that have computer-based quizzes. Students are able to select these books of their interests in the school library, take them out, and read at their leisure. After reading the book, the student returns it and takes a quiz. The library or computer room is available for students to take the Accelerated Reader Quiz before, after, or during school. The facilitator and teacher can access student progress via computer immediately. At RJHS, students are awarded through a school-wide incentive program for their reading progress. One teacher commented, "Data on library usage is up over $50 \%$." As observed at lunchtime, the library was busy with students eager to select another book. The school supports and promotes the Accelerated Reading Program with the school-wide DEAR (Drop Everything and Read) program.

Yet another part of the academic program is the A-Plus program. Like the Accelerated Reading Program, the A-Plus Program is computer based. The Special Education Department largely uses it, but some general education teachers also utilize it. The program provides differential instructional strategies and individual practice for students who are struggling to meet expected learning outcomes. A-Plus is not a voluntary program; instead, students are identified as struggling learners and referred by the classroom teacher.

As stated earlier, most of the instructional materials used by RJHS are purchased from common publishing companies. Another convention guiding instructional practice is the Madeline Hunter Lesson Model. The principal prefers and promotes the Madeline Hunter Model. RJHS teachers use it and are comfortable with it. One teacher commented, "We are primarily asked to use the Madeline Hunter lesson format." The Madeline Hunter Lesson helps teachers present meaningful, well organized lessons that 
include setting objectives, behavioral standards, anticipatory set, lesson presentation, check for understanding, guided practice, closure, and independent practice. This general framework of instructional techniques is fueled by an intense drive to improve schoolwide student achievement. RJHS teachers are driven by internal and external pressures to increase student achievement. These pressures move the staff to continuous collaboration sessions to reflect, compare, share, and brainstorm various instructional strategies that will lead to more effective lessons.

Instructional arrangements at RJHS are innovative and reflect the administration's preference to teamwork. RJHS follows what they describe as a "Modified Block Schedule." The school day begins at 8:45 A.M. with four 40-minute periods and then a 20-minute lunch period, after which are the last three 40 -minute periods of the day. The school day ends at 2:45 P.M. Student organization consists of students of the same grade who are placed with homeroom teachers for the first half of the school day. After lunch, students exchange books at their lockers and then report to the partner-teacher for the last half of the day. Partner-teachers teach the same grade level, but one teaches Language Arts and the other Math/Science. The Language Arts teacher is responsible for Social Science. Students also have ancillary classes such as Physical Education, Computers, Library, and Health. RJHS does not offer Fine Arts as part of the daily curriculum.

This Modified Block Schedule provides many benefits to the school. With careful scheduling, teachers get many opportunities to meet regularly while students are in ancillary classes. By teachers servicing the same group of students, teachers can better assess student needs through reflection, and dialogue. General education teachers have time to meet and work with the special education teachers to better serve the needs of 
struggling students. As observed at RJHS teachers take full advantage of the opportunity to collaborate with each other. Teachers work together to prepare lessons, assembly and trip activities, or other student related activities. With the Modified Block Schedule firmly in place it is apparent at RJHS that teacher isolation does not exist and that strategies, materials, and ideas are not privately controlled but are public property to be shared.

\section{Theme 4: Monitoring, compilation, analysis, and use of data.}

Practices in this theme demonstrate that high performers employ the crucial tool of student performance data to determine how students are performing, to pinpoint each student's specific academic strengths and weaknesses, and to know what instructional techniques and materials are effective. (Luce, 2005, p. 69)

Starting with the Superintendent, RJHS has made a major effort focusing on continuous school improvement through extensive student monitoring, assessment, and the use of data. At the district level, the Superintendent has purchased and implemented the Ed Visions, computerized diagnostic tests in reading and math. The district also hosts teacher workshops and professional developments that focus on how to use data to inform the teaching and learning process. Likewise, the staff at RJHS constantly looks at curriculum goals and assessment data that measure student progress toward attaining these goals. According to the Superintendent:

We start with our goals at the beginning of the school year when we have our kickoff for two days of teacher-in-service. We share the goals for each school with the entire staff. And we go through that by looking at test results.

The entire staff has accepted this quest and work diligently to achieve it.

One form of student assessment used at RJHS is an in-house test called Ed Visions. All students entering RJHS are given the Ed Visions Diagnostic Test in reading and math starting at the beginning of the school and again at the end of the year. The RJHS staff uses this data from their in-house testing in several ways. Initially, the data is 
used to identify students' strengths and weaknesses in order to structure individual learning programs. Next, data is used at the district level in teacher leader meetings to inform feeder schools. The data is compared with year-end results to compute student gains and/or losses. Armed with this valuable assessment data, teachers are able to reflect upon their own instructional strengths and weaknesses and make changes, if necessary. In fact, when a teacher discovers he/she has a concept that a great percentage of students are not grasping, it becomes a departmental concern, and colleagues will help that teacher. RJHS teachers are not embarrassed to acknowledge a problem and ask for help from their colleagues.

Another most important assessment at RJHS is the ISAT. The ISAT is the State's tool for summative assessment, not only of students but of schools as well. Everything at RJHS is geared toward the ISAT test and what they need to do to increase student progress on it. Some teachers even commented that if they discover a concept is not going to be on the ISAT, they will not teach it. As the ISAT tests are taken very seriously, the school has designated Fridays as ISAT Friday. When school resumes after the winter break, ISAT Fridays begin and continue until ISAT tests are administered. On ISAT Fridays, RJHS simulate the ISAT tests using practice tests. Official ISAT testing conditions are strictly followed, complete with proctors and including the timing conditions. These practice tests are scored promptly and later that day immediate feedback and discussions follow. By the time the ISAT tests are administered, students are acclimated to official testing conditions so that test fear is substantially minimized for most students. This practice factor enables RJHS students to perform better on the ISAT tests because they know what to expect. 
Once ISAT test results are received, RJHS staff meets, under the direction of the principal, to share, discuss, and analyze test data. The principal commented, "When we see the ISAT scores, we definitely ask teachers to go through the test, see where the strengths and weaknesses are with regards to the test. If we see that a teacher's weakness comes in, then maybe I could offer support for her to help her become stronger in that particular subject. If we see that our students seem to have most difficulty, then we try to incorporate things to help in that area." One teacher offered a supporting statement, "As classroom teachers we are all asked to look at our scores to see if there is some type of recurring theme. What areas may be a little low or weak? This was for me personally, I looked at my scores and I saw that a lot of my class had problems. So I saw that as a deficiency. Maybe I am not teaching it correctly. Maybe I need to get training on it, or I need to do something different in teaching it in the class." This act of analyzing and reflecting on one's own instructional techniques in a supporting environment can only encourage overall school improvement. It is evident that instruction and assessment have become integral activities that are continually under review and adjustment at RJHS.

Theme 5: Recognition, intervention, and adjustment. "These practices concern how educators in high-performing schools and districts use the information from student performance data to recognize the academic needs of each student and provide immediate and intense intervention to attend to those needs" (Luce, 2005, p. 69). All three aspects of this theme, recognition, intervention and adjustment are evident at RJHS. First, recognition of academic success is a common practice at RJHS. At the end of each grading quarter outstanding students are named as "Top Scholars." Top Scholars are recognized in whole school announcements via the school's public address system, on 
school bulletin boards, and the school yearbook dedicates six pages to commemorate their achievements. In fact, when the principal begins these well-anticipated announcements, the students quickly quiet each other down so that all can be heard. After the announcement, cheering can be heard throughout the entire school coming from classrooms. Similarly, students who participate and excel in the Accelerated Reader Program are recognized as "Top Ten Readers." Top Ten Readers are recognized regularly in morning announcements and bulletin board displays.

Also, in recognition of Top Scholars, a special ISAT Awards Dinner is held to honor students who receive exceptionally high ISAT scores. Even though honorees are no longer students at RJHS, they all return for this recognition dinner. Parents and distinguished people from the community are invited. The ISAT Awards Dinner is held annually in the school gym. The following is a first-hand account of the 2006 ISAT Awards Dinner as experienced by this researcher.

The ISAT Awards Dinner started promptly at 6:30 P.M. in the RJHS gym. Students and teachers were in charge of the guest list at the door. Programs and raffle tickets were issued at the door as guests entered. Although seating was at will, students escorted guests into the gym and a seat. The gym was decorated beautifully with purple and white balloons and looked quite elegant. Balloons formed an archway that stood over a table bearing the certificates of recognition and award packets. Tables adorned with white tablecloths, purple balloons, and flower centerpieces were arranged at the center of the gym. One table toward the front was reserved for the School Board members and other special guests. Around the perimeter of the room were tables of catered food, desserts, and sodas. Teachers and students worked as servers at those tables. 
The ISAT Awards Dinner commanded a large gathering of people, as most tables were filled to capacity. The District Superintendent, her assistant, and board members, some of the district's other principals, parents, student honorees, and teachers attended the event. Special guests included Mr. Tom O'Mally from the Regional Education Office, the city mayor, and a representative of Congressman Jesse Jackson, Jr.

The ISAT Awards Dinner and Program was simply inspiring. Everyone was dressed up, probably in their Sunday best, and on his/her best behavior. One highlight of the program was a PowerPoint presentation of the honored students' pictures of school year memories along with teacher comments. This large screen presentation was accompanied by soft music during the dinner segment. This was a very impressive presentation, and it was well received by students and their guests. After dinner, awards were presented to student honorees by the principal and the students' former teachers. The awards were in the categories of perfect scores and exceeds. Students with perfect scores award included a $\$ 50$ check. All honorees received a letter from Congressman Jesse Jackson, Jr., who usually attends this event but was unable to attend this one. Awards were conferred upon the honorees, as parents and other guests cheered enthusiastically. During the next segment of the program, the mayor was the featured guest speaker. He praised the school administration, teachers and students. He challenged students to pursue higher education and come back to support the community when they become successful in life. During the last segment of the program, the principal made closing remarks, thanking all in attendance, and encouraged students to continue to strive for excellence. She challenged the seventh grade students in attendance to strive to become next year's, honorees. The Superintendent made closing remarks in which she 
praised the principal for her leadership and dedication to RJHS. The program was well organized and received. This writer believes it offers great motivation through excellent incentives and recognition for students.

It is evident at RJHS that high expectations are the norm for all students. To this end, the staff strives to address students' individual educational needs. Student intervention and adjustment is a systemic and on-going practice at RJHS. Over the past few years, RJHS staff, along with the district staff, has been designing a plan that provides a system of interventions for students who are struggling with their schoolwork. This system of interventions is not limited to special education students or the identification and placement thereof; it is for all students who are identified by the teacher as struggling. The principal explained RJHS system of student intervention:

When a student is struggling, initially the teacher is the one who is proactive. They have a form they check off what the difficulties are. They notify the parents that the child [is being placed] on a modified plan. They give a couple of weeks to try some strategies [i.e., interventions]. Now after a couple of weeks, if the strategies do not work, they request that the parents come in and I get involved. A special education teacher and a resources teacher are also involved. We brainstorm on what could be going on. The parents [are informed] that the child can be tested, but we do whatever we can to prevent the child from being labeled as "special ed". We make sure we have exhausted all other possibilities. Because we want to prevent that child from gaining that label.

At RJHS, developing the right intervention plan for a student often involves teachers, the principal, and parents who work together as problem solvers.

\section{Research Question 2}

To what extent is Relational Trust developed in the high performing schools?

Relational trust, so conceived, is appropriately viewed as an organizational property in that its constitutive elements are socially defined in the reciprocal exchanges among participants in a school community, and its presence (or absence) have important consequences for the functioning of the school and its capacity to engage fundamental change. (Bryk \& Schneider, 2002, p. 22) 
The elements that factor into relational trust are basic to all social interactions such as respect, competence, personal regard for others, and integrity. These elements have great impact upon all social interactions and success within any workplace and even more so in a school. The types of adult social interactions or role relations most common in a school are principal to teacher, teacher to teacher, and teacher to parent. Teachers were asked to respond to a trust survey instrument to reveal the levels of trust and confidence held in the principal, between each other and parents. Fourteen teachers out of a total of 25 volunteered to complete the trust survey. That is approximately $56 \%$ of the teacher staff. Tables 1-3 show RJHS's observation and survey results.

\section{Table 1}

Teacher-Principal Role Relations

\begin{tabular}{cccc} 
Not & & To a Great & No \\
At all A Little & Some & Extent & Answer \\
\hline
\end{tabular}

1. It's OK in this school to discuss feelings, worries, and frustrations with the principal. $\quad \begin{array}{llllll}0 \% & 0 \% & 21 \% & 71 \% & 7 \%\end{array}$

2. The principal looks out for the personal welfare of the faculty members.

$\begin{array}{lllll}0 \% & 0 \% & 7 \% & 92 \% & 0 \%\end{array}$

3. I trust the principal at his or her work.

$0 \% \quad 0 \% \quad 0 \% \quad 100 \% \quad 0 \%$

4. The principal at this school is an effective $\begin{array}{lllll}\text { manager who makes the school run smoothly. } 0 \% & 0 \% & 7 \% & 85 \% & 7 \%\end{array}$

5. The principal places the needs of children ahead of her personal and political interests. $\quad \begin{array}{lllll}0 \% & 0 \% & 28 \% & 71 \% & 0 \%\end{array}$

6. The principal has confidence in the expertise of the teachers.

$\begin{array}{lllll}0 \% & 0 \% & 28 \% & 71 \% & 0 \%\end{array}$

7. The principal takes a personal interest in the professional development of teachers.

8. I really respect my principal as an educator. $\begin{array}{lllll}0 \% & 0 \% & 14 \% & 85 \% & 0 \%\end{array}$

9. I feel respected by my principal.

$\begin{array}{lllll}0 \% & 0 \% & 0 \% & 100 \% & 0 \%\end{array}$

$\begin{array}{lllll}0 \% & 0 \% & 21 \% & 78 \% & 0 \%\end{array}$


On the Teacher-Principal Trust Survey, RJHS teachers reported a great deal of trust in the principal; in return, $71 \%$ of the teachers reported that they feel a great deal of respect. On the survey, teachers indicated that the principal takes an interest in their professional development, has confidence in their teaching, and looks out for their welfare. RJHS teachers strongly agreed that the principal is an effective manager who makes the school run smoothly. More than $92 \%$ of the teachers strongly agreed that the principal places students' needs first. A remarkable $100 \%$ of the respondents trust the principal as an educator and believe very strongly that she can do the important work of a school leader. The results of this survey indicate a very strong teacher-principal trust ratio at RJHS.

Table 2

Teacher-Teacher Role Relations

\begin{tabular}{lccc} 
Not & & To a Great & No \\
At all A Little & Some & Extent & Answer \\
\hline
\end{tabular}

1. Teachers in this school really care about each other.

$0 \% \quad 0 \% \quad 50 \% \quad 42 \% \quad 7 \%$

2. Teachers in this school trust each other.

$0 \% \quad 0 \% \quad 71 \% \quad 28 \% \quad 0 \%$

3. It's OK, in this school, to discuss feelings, worries, and frustrations with other teachers. $\quad \begin{array}{lllll}0 & 14 \% & 50 \$ & 35 \% & 0 \%\end{array}$

4. Teachers respect other teachers who take the lead in school improvement efforts.

$0 \% \quad 0 \% \quad 28 \% \quad 71 \% \quad 0 \%$

5. Teachers at this school respect those colleagues who are expert at their craft.

6. I feel respected by other teachers.

$0 \% \quad 0 \% \quad 35 \% \quad 64 \% \quad 0 \%$

7. In this school, teachers have a "can do" attitude.

$\begin{array}{lllll}0 \% & 0 \% & 35 \% & 64 \% & 0 \%\end{array}$

8. Experienced teachers invite new teachers into their rooms to observe, give feedback, etc.

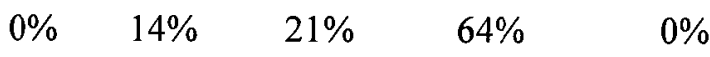

9. Teachers in this school are willing to take risks to make this school better.

$\begin{array}{lllll}0 \% & 0 \% & 28 \% & 71 \% & 0 \%\end{array}$

$\begin{array}{lllll}0 \% & 0 \% & 35 \% & 64 \% & 0 \%\end{array}$


On the Teacher-Teacher Trust Survey, RJHS teachers indicated a great deal of respect among their colleagues and also for those teachers who are expert in their subject areas and teachers who take leadership roles in school improvement process. Seventy percent of RJHS teachers reported that they trust each other somewhat, while $28 \%$ indicated a great deal of trust in each other. More than $50 \%$ of RJHS teachers indicated care for each other and confide in one another. While teacher-teacher results indicated strong trust levels between teachers, the trust teachers have for the principal surpassed teacherteacher trust.

Table 3

Teacher-Parent Role Relations

\begin{tabular}{|c|c|c|}
\hline $\begin{array}{l}\text { Not } \\
\text { At all }\end{array}$ & Little & ome \\
\hline
\end{tabular}

1. How many of your students' parents do their best to help their children learn?

\begin{tabular}{lllll}
\hline $0 \%$ & $43 \%$ & $43 \%$ & $7 \%$ & $7 \%$ \\
\hline $0 \%$ & $50 \%$ & $7 \%$ & $35 \%$ & $7 \%$ \\
\hline $0 \%$ & $32 \%$ & $21 \%$ & $50 \%$ & $7 \%$ \\
\hline $0 \%$ & $32 \%$ & $21 \%$ & $35 \%$ & $7 \%$ \\
\hline $0 \%$ & $21 \%$ & $50 \%$ & $21 \%$ & $7 \%$ \\
\hline $0 \%$ & $57 \%$ & $28 \%$ & $7 \%$ & $7 \%$ \\
\hline $0 \%$ & $7 \%$ & $21 \%$ & $64 \%$ & $7 \%$ \\
\hline $0 \%$ & $0 \%$ & $42 \%$ & $50 \%$ & $7 \%$ \\
\hline
\end{tabular}

. How many teachers at this school feel good about parents' support for their work?

3. How many teachers at this school really care about this local community?

4. How many of your students' parents support your teaching effort?

5. Teachers and parents think of each other as partners in educating children?

政

6. There is conflict between parents and teachers at this school.

7. Parents are invited to visit classrooms to observe the instruction program.

to

8. Teachers really try to understand parents' problems and concerns.

(n)


On the Teacher-Parent Survey, RJHS teachers reported moderate levels of confidence in parents to do their best to help their children learn and to support teachers. The teachers reported a great deal of concern among colleagues for the local community and perceived teachers and parents as partners in educating children. Teachers reported a moderate level of conflict exists between parents and teachers but most teachers indicated that they try to understand parents' problems and concerns. While the Teacher-Parent Survey revealed the lowest levels of trust by comparison, the overall percentage of trust in this area was relatively strong.

\section{Research Question 3}

To what extent is instructional program coherence developed in the high performing schools?

Instructional Program Coherence is defined as "a set of interrelated programs for students and staff that are guided by a common framework for curriculum, instruction, assessment, and learning climate and are pursued over a sustained period" (Newmann, Smith, Allensworh, \& Bryk, 2001, p. 299). Instructional Program Coherence requires a clear and strong instructional focus that is school wide. It also requires school wide accountability and collective efforts of the entire school community. Newmann, Smith, Allensworth and Bryk (2001) identified three major conditions that must prevail for Instructional Program Coherence to exist in a school. These conditions are (a) a common instructional framework, (b) staff working conditions support the framework, and (c) allocation of funds, materials, time, and staff assignments support the framework. Robinson Junior High School's results will be reported in accordance to these three identified conditions. The Instructional Program Coherence Rubric used to analyze teacher responses was adapted from Newmann, Smith, Allensworth and Bryk (2001) and 
reflects the initial results from RJHS. This rubric was used by the researcher as a guide for conducting interviews of teachers at RJHS.

Prevailing condition 1. The first prevailing condition was "A common instructional framework guides curriculum, teaching, assessment and learning climate. The framework combines specific expectations for student learning, with specific strategies and materials to guide teaching and assessment" (Newmann, Smith, Allensworth, \& Bryk, 2001, p. 299). A series of rubric items were used to probe the principle that schools should have a common instructional framework that guides curriculum, teaching, assessment, and learning. Teachers at RJHS indicated that the school's entire curriculum is aligned to the Illinois State Board of Education Learning Goals. In fact, every teacher who was interviewed stated that the curriculum was aligned to state goals. One teacher commented, "We meet by subject area and align our curriculum to the state standards. The principal requires us to write down the state goals in our lesson plans so every lesson is related to a state goal." Another teacher stated, "One thing that we do here is take the state standards, we look at the state standards and we align our curriculum towards the state standards." As revealed through interviews and observation, the entire staff believes in and supports the common curriculum. The teachers at RJHS are constantly revisiting and revising the curriculum to reflect state learning goals and assessment changes.

Teachers at RJHS use some common instructional strategies and are always eager to share a successful strategy with a colleague in need. One teacher shared that, "We are primarily asked to use the Madeline Hunter Lesson Format." The principal stated this during her interview as well. While the lesson format is the Madeline Hunter Format, a lead teacher commented that, "Each teacher is different in his/her method of delivery but 
teachers here do share strategies that work well." Another teacher added that, "We all use our strengths in different ways. However when someone needs help or ideas I find that other teachers are more than willing to share ideas, resources and suggestions." While teachers at RJHS celebrate and share their unique styles of teaching, they do use a common instructional format in which to organize their lessons.

RJHS teachers within a grade use some common assessment strategies. "The only common assessment we use school wide is the ED Visions Test and ISAT. Teachers use the textbook series tests in a self-modified format," commented one teacher. As explained by the principal, the ED Visions Test of reading and math is administered to students during the first weeks of the new school year and again near the end of school. ED Visions Test data is used to identify student needs and remedial services are organized. The test is given again near the end of the school year to measure student growth and to inform school improvement planning. The ISAT is administered according to the Illinois State Board of Education schedule, which usually occurs in March or early April. ISAT data is also analyzed and used to inform school improvement planning. All of the teachers interviewed commented on the textbook series tests. One teacher commented that, "The math series comes with a test generator disk so you can go in and pick or choose your own questions." Another teacher commented that,

I do not use publisher tests. I teach based on the ISAT and some parts of a chapter I may skip; however, it may be covered on the publisher's chapter tests. It is not fair to students to include things on a tests that were not covered so I create my own tests based on what I taught.

While teachers have indicated a strong school wide curriculum focus, it appears that the assessment component is not as strong. 
Teachers at RJHS work diligently to coordinate all curriculum and many assessments across the grades to avoid repetition as students move from grade to grade. Teachers meet regularly to discuss and coordinate curriculum at all subjects and levels. "In our subject area meetings are where we coordinate curriculum and assessment. We meet once monthly on Fridays and during the summer. We do communicate vertically between seventh and eighth grade during our subject area meetings," explained a teacher. Another teacher stated,

I think subject area teams are one of the best things that the principal set up. Math teachers from both seventh and eighth grades meet regularly. The eighth grade teachers have stated to the seventh grade teachers that, "this is what we need you to cover, these concepts well so kids are coming to eighth grade ready to do eighth grade work.

The interviews even revealed vertical meetings with the elementary and high schools that feed into RJHS. One teacher explained:

Our math-science team leader, Mrs. B attends the district level meetings where she is able to voice what students are expected to know and be able to do when entering RJHS. Mrs. B also meets at the High School district level where the same types of conversations are addressed.

Teachers from the language arts department expressed similar accounts of district-level meetings.

All RJHS-sponsored support programs are linked to the curriculum, instruction, and assessments. Remedial instruction programs are offered in reading and math. "We offer Homework Club, After School math and reading and math and reading acceleration. Math and Reading chosen because ISAT data indicated improvement was needed," explained one teacher. Another teacher commented, "Many teachers come early or stay late to provide small group tutoring and remedial work with our own students to try and bring them where they need to be." School assemblies are connected to history, reading, 
science, or math and give students opportunities to showcase their knowledge in these areas. "With the assemblies that we have, they are always educational and there is some goal like history, or student motivation. We never assemble students just to have an assembly with no good educationally based focus," proudly stated one teacher. Field trips are organized for student incentives and motivation as stated by a teacher, "We have incentive trips and those are more for rewards to students who met certain criteria will go." Field trips at RJHS are organized by grade level teams and must be approved by the principal. While teachers report that parent involvement is minimal, the school does provide opportunities for parent to take part. A teacher explained:

We have ISAT Night where parents are invited out and shown the type of questions that are on the ISAT and we give them a practice test. We let them know the things the students are expected to know. We do not get a good parent turn out.

The school also invites parents to the school's Open House, school assemblies, and all other events. RJHS teachers and staff make repeated efforts to provide opportunities to involve parents, but they acknowledge that it could be better.

Prevailing condition 2. The school staff's working conditions should support the implementation of the common instructional framework. Teachers explained that some Professional Development (PD) Workshops were sponsored by the district, while other PD Workshops were school sponsored. Teachers may also request to attend a PD Workshop by completing a formal request form. At RJHS all Professional Development Activities support the common instructional framework or it will not be approved. This rule is known and accepted by all RJHS educators. According to one teacher:

Before we can do any kind of workshop or professional development we have to fill out this sheet that says this will help me in the curriculum and how or this will 
help in school goals and how. All workshops that we attend must have some learning on the school curriculum or school goals.

Another teacher commented that, "It is almost guaranteed that if you go to a workshop that you have to present it to the team during the curriculum meetings." Many professional development programs are sustained over time, but not all. Educators at RJHS strategically select and implement new programs that they collectively feel are successful. To quote one of the lead teachers, "Some PD are sustained and some are not. It is a team decision." Teachers gave several examples of programs that had been adopted and sustained by RJHS. Some of those mentioned were RAMS Reading and, most recently, RAMS Math, A Plus Program, ISAT Math Strategies, Accelerated Reader and Math at the Breakfast Club, and the Homework Club, to name a few.

At RJHS, school improvement planning and assessment addresses the school's progress in providing sustained programs. School improvement planning at RJHS is a team effort. The school has a SIP Team which meets to discuss and reflect on the school's progress toward its goals. According to one teacher, "The principal comes to us with goals or things that need to be accomplished during staff or subject area meetings. Many school goals are generated because ISAT data indicates improvements that need to occur." Another teacher's perspective of the SIP Team is:

The SIP Team focuses on what we need as a school and what students need to be able to do and learn in the 2 years they are here and how we need to prepare them for High School. How to get parents and community more involved.

Through the principal's oversight, RJHS's educators are on target with providing meaningful PD for the staff as well as reflecting and moving the school toward its goals. 
Prevailing condition 3. The third prevailing condition is:

Allocation of funding, materials, time and staff assignments to advance the school's common instructional framework and to avoid diffuse, scattered improvement efforts, with the following results: (a) Curriculum and student assessments remain stable over time, (b) Teachers' professional assignments are stable enough that teachers have sustained opportunities to learn how to teach well in their specific roles. (Newmann, Smith, Allensworth, \& Bryk, 2001, p. 300).

A school's administration should allocate funding, materials, time, and staff assignments to advance the school's common instructional framework. The curriculum at RJHS has been very stable over time and teachers have sustained opportunities to learn how to teach most of it quite well. That is the overall opinion of teachers at RJHS.

Assessment at RJHS has become somewhat problematic in the past year. The three main assessments used at RJHS are Ed Visions, ISAT, and teacher-modified publisher tests. These assessments have been stable; however, teachers are experiencing problems interpreting the ED Visions assessment. One teacher did comment that, "They have changed the Ed Visions Tests. In the past, we were able to see where the kids were in reading and math with percents for a grade level. Now it is something totally different and we cannot interpret it." The district is currently looking for another diagnostic testing system. Educators at RJHS do make minor changes to the curriculum based on ISAT changes, but acknowledge that the curriculum is very stable. Similarly, assessment at RJHS is fairly stable and teachers have had opportunities to learn how to teach students to succeed on them. To quote one teacher, "Our curriculum and assessment is ISAT focused. We make changes when test trends change." Through observations and interviews, it becomes apparent that funds are allocated toward schools goals, as well as materials needed, time, and staff stability are the norm at RJHS. 


\section{Research Question 4}

What is the influence of the principal's leadership style on the staff and school climate?

School leadership is one of the most important factors that influences a school's success. The principal is the immediate leader of a school and must manage several different aspects of the organization from the instructional program to the day-to-day building operations. Moreover, the principal is a role model in a school and his/her attitude sets the tone for all others to follow. Today's school leadership is different from the top-down models of years past. School leadership today seeks to utilize a team approach involving the principal, teachers, and parents as partners who share in making important decisions to guide the school. Leadership at RJHS is anything but top-down or authoritative; rather, the leadership is open, shared, and viewed as a partnership by the staff. The Illinois Best Practice Framework cited strong leadership practices that were observed in high performing schools as "having an instructional focus, sharing school leadership, setting visionary and clear goals, and being highly motivational." Leadership practices at RJHS will be discussed accordingly to the competencies cited by the framework.

Instructional leadership. The district leaders and principal are focused on instructional program management. Under the direction of district and school leadership, RJHS has aligned their curriculum to the Illinois State Learning Goals and created a common instructional framework that guides the curriculum, instruction and assessment for all grades. Teachers at RJHS are included in most curricular and instructional decisions and are, therefore, very supportive of the framework and willing to go the extra mile to ensure the school's success. The principal and most teachers stated that the 
instructional program is ISAT focused. For RJHS this means that if a concept was not on the ISAT, then not much time would be spent teaching and assessing that concept. While the school is ISAT focused, the principal made it clear that it is not their only focus. The school is also focused on the success of the students. To quote one teacher,

While we do try to prepare students for ISAT, that is not just the focus of our curriculum, we also realize that kids have to go to high school so we also try to improve skills that will make them successful in high school; not just ISAT scores.

At RJHS, the principal creates opportunities for the teachers to work on teams. In fact, the principal is very team oriented and has established several teacher teams in the school, such as grade level teams, subject area/curriculum teams, leadership team, and the school improvement team. While the principal does not attend every team meeting, it is expected that the team should meet and provide meeting notes to the principal regularly. The principal is a regular part of the leadership team and the school improvement team meeting. Through block scheduling time is provided for team meetings, some meetings are scheduled before or after the school day. The teachers are mostly supportive of these meetings and eager to comply with expectations. These teams help to guide the school, reflect on practices, monitor student progress, revise or set new goals, and many other positive benefits to the school. By working on these flexible teams, RJHS teachers have become closer and more respectful of each other's strengths and weaknesses. To quote another teacher,

I have no qualms about anyone of the teachers giving me some advice. We are not going to bicker about each other. If you are absent you may come back with little notes in the mailbox saying hope you are feeling better. We do a lot together.

This type of camaraderie makes RJHS a delightful and engaging educational setting to visit. 
Open dialogue, shared school leadership and shared decision-making are the norm at RJHS. Through teams, faculty meetings, and the principal's open door policy, teachers at RJHS have gained a strong voice in all decision-making. To quote a teacher about the principal's open door policy, "It is actually really easy to approach the principal." The principal is an advocate of teamwork and promotes team activities in the school. The school improvement team (SIP team) and the leadership team consist of teachers who represent their grade level interests, and/or subject areas. One teacher shared these comments during an interview:

We have a group of teachers who serve on the SIP team and suggestions taken from the staff goes to the SIP team. When the SIP team meets, we pull these suggestions out. If it is something that we think should be addressed, then we talk about it as a team. We try to come with some kind of plan or strategy then take it back to the staff.

As observed, ideas are presented to the staff during staff meetings, at which time a discussion of pros and cons ensues and eventually a vote by the school staff. One teacher made this statement, "The principal presents ideas to the teachers then we have a forum discussion and vote." Another teacher firmly stated, "We have a wholesale buy-in to new programs here but with different degrees of commitment involved. Everybody will run the program, but some will run it at a high level while others at a minimum level." This teacher also commented that, "I cannot think of a program that was put on us. When new programs are brought to us, we are allowed to accept them." All teachers who participated in the interview or the survey indicated great satisfaction in the school's decision-making processes.

Visionary leadership. The principal and teacher leaders are able to set goals and communicate expectations. The principal explained that goals for RJHS were developed 
based on student need as indicated on ISAT or school climate factors. To quote one teacher:

The principal comes to us with goals or things that need to be accomplished during staff or subject area meetings. We discuss and address those issues make a plan and move on from there. Many schools goals are generated because ISAT data indicates that need to occur.

Some of the goals set for RJHS included prioritizing math improvement throughout the school as well as student behavior, while continuing efforts in reading goals set previously by former school leaders. To accomplish the math goals, math teachers met during summer prior to the school year to design a math skills program similar to the RAMS program used to improve reading. The math RAMS was implemented school wide that new school year. Another goal set by leadership was to focus on improving student behavior and attendance. To accomplish this goal, the Dean of Students began tracking student infractions and made a weekly report of these infractions during the faculty meetings. Armed with this information, teachers were advised how to counteract future occurrences.

The principal sets clear expectations for individuals, but she also has high expectations for teacher groups such as teams and partners. The following is an observation account of a seventh grade staff meeting when the principal addressed the seventh grade teachers after weeks of monitoring activities.

The Principal and Dean met with the seventh grade teachers. The principal started out expressing her disappointed with the seventh grade teams. The principal pointed out that there was no teamwork or team spirit among them, but lots of isolation, lots of teacher inconsistency with following school rules, and more behavior problems recorded among seventh grade students. The Dean added that seventh grade students were not being given hall passes and the seventh grade hallways were noisy and chaotic. The principal asked for teacher comments; there was none. The room was quiet and tense. 
The meeting continued with the principal restating her expectations for team and partner meetings and her plan to meet with each teacher individually in the upcoming weeks. As observed, the principal clearly stated her expectations and her plans to monitor them.

Motivational leadership. Leadership at RJHS expresses a positive attitude and sets high expectations for students and staff. At RJHS, one can immediately sense the friendly school climate upon entering. Office staff and the principal greet visitors warmly when they enter the office. The principal greets teachers and students as the school day begins. As observed, the principal knows many of the students' names and addresses them by name when she encounters them throughout the day. The principal sets high expectation for staff and students in part by the way she goes beyond expectations to perform her own duties.

The principal is accessible to teachers and students and is visible in the school building and school grounds. In fact, the principal is seldom in her office during the school day. Instead, the principal can be found observing classrooms and taking an active part in daily student entry and dismissal. The principal indicated that she believes strongly in supporting teachers in the classrooms so she spends a lot of time in classrooms, especially with new teachers. It is readily observable that during the school day the principal can be found monitoring hallways and classrooms rather than sitting in the office. After school, the principal walks several blocks from the school to ensure safe passage for her students. In fact, because of her great efforts, the police are also involved with student dismissal by patrolling the route by car and reporting to the principal when there are any problems and when most students have cleared at the furthest points. It is then that the principal returns to the school. 
At RJHS, the principal values teachers and staff and they also value her. As indicated on the Teacher-Principal Trust Survey (Item \#2), 100\% of the teachers surveyed believed that the principal looks out for the personal welfare of the faculty members and felt respected by the principal (Item \#9). The principal values teacher input in the school's decision-making process by including teachers in the hiring process, by seeking their comments, concerns and votes before implementing new programs, and treating them with respect. The principal shared these thoughts about her job:

I love teaching and I love education. I love what I do. There is just no doubt about it and I give everything that I have into it. I sit and meditate and think about what can I do to give these children the best possible education. My relationship with people is very important. I think you should treat people with respect and that is how I want to do this. We are not perfect individuals, but I value life and I value people.

This principal's love for her job and value of her staff shows throughout the entire school as teachers volunteer their time to tutor students before and after school, work Saturday morning detention, and use their own spare time to run Market Day Sales fund raiser activities. Even students linger around after school socializing with friends and staff.

\section{Research Question 5}

How do the five themes of the Illinois Best Practice Framework, instructional program coherence, and relational trust contribute in creating a professional learning community?

The contributory impact of the five themes of the Illinois Best Practice

Framework, instructional program coherence, and relational trust is that these concepts are embedded within the practices of a professional learning community. Moreover, all these concepts are interdependent and must all work simultaneously for any school improvement to result. To explain this connection, one must first understand what a PLC is and its most salient characteristics. A PLC is a school where all stakeholders work 
collectively toward the success of the school. The most salient characteristics of a PLC are shared mission, vision and values, collaborative school culture, collaborative teams, shared decision making, shared school leadership, collective inquiry, common planning and preparation time, and a focus on student learning and results (Dufour \& Eaker, 2005). These concepts will be discussed according to the five themes of the Illinois Best Practice Framework and how instructional program coherence and relational trust contribute in creating a PLC.

The first theme of the Illinois Best Practice Framework-Curriculum and Academic Goals — establishes the practice, in high performing schools, of creating clear and specific academic goals that all educators agree upon and are held accountable for. One important characteristic of the PLC is for all stakeholders in the school to collectively establish a shared mission and vision that clearly articulates what they intend to accomplish, what they believe in and value. These statements are the catalyst for all the other goals to come, because one must know what the intended outcomes are before any viable plans can be developed. At RJHS, the school's mission and vision statements are posted in every classroom. The school's mission and visions are revisited often and all new staff members are orientated on these guiding principles. These guiding principles pave the way for academic goals to be established and curriculum development and alignment completed.

The second theme of the Illinois Best Practice Framework-Staff Selection, Leadership, and Capacity Building — establishes the importance of practices that involve creating an effective school community. This theme relates to the practices in a PLC involving widespread leadership and shared decision-making. In a PLC, a team of 
teachers and the principal interviews candidates and makes decisions regarding new staff selection. Collaborative teams are a common practice at RJHS as is widespread leadership, which seeks to involve teachers in decision-making. Widespread leadership also involves empowering teachers by building their capacity for leadership, teamwork, and more through professional development and active participation.

The third theme of the Illinois Best Practice Framework-Instructional Programs, Practices, and Arrangements—concerns the instructional program and the provision of instructional materials, time, and technology. The PLC connects with this theme in many of its characteristics beginning with widespread leadership. In a PLC, decisions regarding instructional programs, practices, arrangements and technology choices are made collectively through collaborative teams. Principals who support the PLC avoid making top-down decisions but seek the input of teachers who are actually affected by the choices. Shared school leadership recognizes the importance of collaborative teams and thus provides time for common planning and preparation for teachers and technology needs. This common planning and preparation time affords teachers time to learn from each other, share successful instructional practices, plan common assessment, establish common grading criteria, collective inquiry and so much more. In a PLC there is a continuous commitment for improvement that drives members to constantly reflect on practices and arrangements, such the instructional program, to ensure that school goals are met.

The fourth theme of the Illinois Best Practice Framework-Monitoring: Compilation, Analysis, and Use of Data—concerns how students are performing; it seeks to identify and address students' academic strengths and weaknesses. The practices in 
this theme are also at the heart of practices in the PLC, such as to focus on student learning and results. PLC practices begin with a guiding mission and vision statement and next set clear academic goals that clarify what students are expected to learn. Then student learning is monitored on a timely basis through common assessment and grading criteria. Student work is reflected upon during common planning and preparation time. Students' academic strengths and weaknesses are identified and addressed. In a PLC, this is also the time to identify strengths and weaknesses in instructional techniques. It is all a part of the continuous improvement quest that drives the PLC.

The fifth theme of the Illinois Best Practice Framework-Recognition, Intervention, and Adjustment — concerns providing intervention and adjustments for students who require such services. The connection of this theme to the PLC lies in the focus on student learning and results as well as the continuous improvement practices. The focus on results in the PLC practices specifically seeks to judge instructional effectiveness based on assessment results and to create systems to insure students receive support if they are not learning. To support this effort, PLC collaborative teams are an integral part of the monitoring and intervention process. The professional learning communities quest for continuous improvement keeps the cycle of collective inquiry, monitoring, common planning, etc. ever moving.

The concept of Relational Trust permeates every aspect of the PLC. Relational Trust is the staff's willingness to work collectively with one another trusting and respecting each other's professional skills and abilities all working toward and valuing the success of the organization. "Without trust among faculty, change efforts may become contrived and lack lasting impact. For these reasons, we hypothesize that social 
trust is another key facilitating factor for professional community" (Bryk, Camburn, \& Louis, 1999, p. 757). One PLC characteristic that really encompasses the ideas of Relational Trust is collaborative school culture. Relational Trust directly impacts school culture, as it involves the social interactions of all people within the school. When people feel valued, respected, and are a valuable part of the organization, they are more willing to support and participate in the hard teamwork necessary for collective school improvement efforts. High levels of Relational Trust make a friendly school culture whereby the staff can work together to create a mission and vision that will guide the curricular and academic goals, set norms for collegial support, maintain mutual support for instructional programs, and monitor for continuous improvement. Relational Trust is so dynamic that it can make or break any school or organization.

\section{Summary: An Emerging Professional Learning Community}

The educators at Robinson Junior High School have made significant progress over the last few years in becoming a more successful school. Practices cited in the five themes of the Illinois Best Framework, instructional program coherence, and relational trust help to identify many of the organizational practices of a PLC and those used by educators at RJHS that account for many of the school's improvements. Administrators and teachers have developed a mission and vision for the school that guides the hearts, minds and work of all stakeholders. There is a great sense of camaraderie that enables the collaborative teams to focus on the continuous work of curriculum alignment, instruction, and assessment. Clear and specific academic goals are in place to guide the process. Teachers are open to professional development opportunities and eager to share new strategies that support the school's quest for continuous improvement. The school 
climate is warm, school operations are orderly, and the environment is quite conducive to learning.

There is a strong sense of caring observed at RJHS that accounts for a cycle of continuous social interactions on all levels. Teachers volunteer to do activities outside of classroom duties in the school and even use personal funds. One teacher, who is artistically inclined, enjoys decorating the bulletin boards in the hallways. Another teacher with musical skills leads a school choir. The Dean enjoys basketball, so he opens the gym after school for students to join him. Other teachers and some parents work together to run the Market Day Fund Raiser for the school, and the teachers are among the biggest purchasers of the products. All teachers support and take turns volunteering their time to facilitate the Saturday morning detention program. The school has a Social Committee that plans social activities for the staff such as Friday night outings where they meet at agreed upon places to eat and socialize. The special benefit, generated by these social interactions, is a strong collegial spirit that keeps all stakeholders focused on the success of the school. A strong professional learning community is emerging at RJHS, which is lead by a highly dedicated principal who embodies the principles and practices of high performing schools.

The principal is highly respected and valued by teachers, student, and parents as evidenced by the survey results. She is respected because they know she cares about them and puts the interests of students before her own. Teachers have commented on her caring nature and generosity as experienced in their times of personal crisis. Her work ethics are exemplary as she spends long days at the school, often working into the night. This principal does not run the school from her office chair but by getting into the 
classrooms, hallways, and team meetings to help wherever she is needed. By continually giving the extra effort in her position, it inspires her colleagues to do the same as witnessed by so many teachers volunteering to do extra things around the school. The principal is truly a leader who leads not by charismatic talk but by example.

To summarize, the principal being a strong advocate of teamwork, has motivated teachers to become supportive of the collaborative school culture necessary for the team spirit found at RJHS. Teachers work together as members of various teams throughout the school with shared commitments, mutual support, extra effort, and a sense of urgency about improving student achievement and preparing students to succeed in higher education. RJHS embodies the characteristics of a PLC. 


\section{CHAPTER V}

\section{CONCLUSIONS, IMPLICATIONS, AND RECOMMENDATIONS}

This chapter discusses and analyzes the empirical results of this study and relates these findings to current educational literature. The chapter starts with an overview of the study, which includes a statement of the problem, the design of the study, and a description of the school. Findings gleaned from this study are presented in accordance with the five research questions developed to guide the research process. Next, implications and recommendations for practice and future research are rendered based on the data and evidence collected throughout the study. Finally, the conclusion will place the study in larger context of the unfinished work of the Effective School Movement.

\section{Overview of the Study}

\section{Statement of the Problem}

Many urban schools are failing the students they serve, while other schools in similar urban settings are excelling. For the past 40 years, researchers have examined various effective school correlates that result in high student performance. These correlates are considered to be important and frequently incorporated in state mandates and district policies. Experience has revealed that adoption of these correlates is only the first step to academic success. Other indigenous factors such relational trust, and instructional program coherence must also be considered in any account of sustained high quality school performance. This study examined a high performing school in accordance with 
the National Center for Educational Accountability (NCEA) Best Practice Framework's five themes and organizational properties of relational trust and instructional program coherence. This study examined contextual factors that contribute to a professional learning community that cultivates and supports the five NCEA themes, relational trust, and instructional program coherence.

\section{Design of the Study}

As an extension of a national research study to analyze exemplary schools using the NCEA Best Practice Framework (Appendix B), this study extended the initial field study used in the larger study. Specifically, a qualitative case study approach was chosen for this study in an effort to document specific practices that make an effective urban school. This study involved an in-depth study of one school in an effort to identify and analyze the indigenous practices that make an effective urban school despite high poverty levels and a significant minority student population. The research design examined a high performing school in accordance to the five themes (Curriculum; Staffing; Instruction; Monitoring Student Progress; and Recognition, Rewards \& Intervention) documented by the NCEA Best Practice Framework and to identify the existence of instructional program coherence, relational trust and leadership style. The research involved one high performing urban school site and utilized observation, interview, and survey instruments to document the indigenous practices there.

The study was conducted in three phases. Phase I involved the original study conducted by the Illinois State University research team. The team made the site selection and conducted fieldwork at the district and school. Phase II of the study centered on this researcher's study of the school's policies, curriculum, instructional 
practices, personnel, and related artifacts. Phase III of the study involved a detailed analysis of interview data, artifacts, and field notes.

\section{Description of the School}

Robinson Junior High School, the study site, is located in a suburb south of a large metropolitan urban city. This modest working class community received thousands of low-income families over the years from the urban city. Robinson Junior High School is nestled into a community that is predominately African American and economically challenged. The school serves seventh and eighth grade students and shares the building with an elementary school. The staff is friendly and eager to assist visitors. The hallways are quiet and orderly. Hallway bulletins are decorated with student work, pictures of students, with decorative borders.

The school has 10 seventh grade classrooms, 10 eighth grade classrooms, and 2 self-contained special education classrooms. The school has a staff of 20 regular education teachers, 2 special education teachers, 15 ancillary staff, 4 support staff, a dean, and a principal.

\section{Summary of Findings and Conclusions}

\section{Research Questions 1}

To what extent are the five themes of the NCEA Best Practice Framework developed in the high performing school?

Theme 1: Curriculum and academic goals. Robinson Junior High School's curriculum and academic goals are aligned to Illinois State Learning Standards and documented in curricular guides. Curriculum and assessment are linked. The curriculum guides are revisited for possible revisions yearly. The teachers widely accept the curriculum and use it. Teachers hold each other accountable to follow a timeline of 
instruction and assessment as indicated by the curricular guides. The school has curriculum meetings with designated teacher leaders who are supported by all teachers.

Theme 2: Staff selection, leadership, and capacity building. RJHS has established procedures for recruitment and retention of highly qualified staff that involve a team approach based on grade level and subject area. There is a district and a strategic school mentor system in place to assist new staff. The principal and dean also support new teachers.

At RJHS, the principal meets with new hires starting in the summer to acclimate them to the school's instructional program and expectations. The principal encourages and nurtures teacher leadership and teamwork. The teachers respect the principal's skills, knowledge and compassion. One teacher commented that the principal is always straightforward with people. The principal has an open door policy and makes time for teachers who request advice.

Teacher isolation is not an option at RJHS, because teacher partnerships are assigned by the principal and nurtured each year. Also, many opportunities are provided for teachers to meet and share ideas. For example, teachers are provided common planning time, and time to meet by grade level and subject area weekly. The school and district both sponsor professional development for teachers. Teachers also have the option to take individual professional development with principal approval. Teachers are expected to share new professional development information with colleagues via scheduled team meetings.

Theme 3: Instructional programs, practices, and arrangements. RJHS has a strategic student discipline program that is widely accepted and practiced by all the staff. 
The school follows a modified block schedule, developed to support the academic and instructional arrangements. The School Improvement Program is implemented and revisited often throughout the year. As literacy improvement was identified in the School Improvement Program, the school purchased a reading improvement program for low achievers, which the staff adapted to school needs and renamed it the RAMS Program. The school also bought the Accelerated Reading Program to encourage independent reading among students. This program resulted in significant improvement in reading, so the school's math leaders developed a RAMS math program. The school also purchased the A-Plus program, a computer-based instruction for struggling learners.

Theme 4: Monitoring, compilation, analysis, and use of data. RJHS uses ED Visions Diagnostic Test, a computer-based assessment program, to monitor student progress throughout the school year. Students are assessed at the start of the school year and in middle of the school year. Test data are used to identify struggling students who are then placed in remedial tutoring offered before or after school. The school also analyzes and uses Illinois State Achievement Test (ISAT) data to identify strengths and weaknesses in curriculum and instruction. The school plans professional development programs and other activities to address any areas of instructional weakness.

Theme 5: Recognition, intervention, and adjustments. Recognition of academic success is a common practice at RJHS. Students are recognized as Top Scholars via the public announcement system, on school bulletin board displays, in the school yearbook, school newsletter, and in awards ceremonies. Students who excel in the Accelerated Reader Program are recognized monthly as Top Ten Readers via public announcement, a bulletin display, and school newsletter. Top Scholars and students 
whose achievement exceeds the average score on the ISAT are recognized at an ISAT Awards Dinner sponsored by the school with parents and local dignitaries in attendance. Intervention is provided to struggling learners in the form of additional tutoring, individual education computer based lessons, or special education services.

According to Luce and Thompson (2005), "Studies of hundreds of school systems across the country enabled researchers at the National Center for Educational Accountability/Just for the Kids to pinpoint five central themes around which high performing schools and districts focus their instructional practices" (p. 67). Based on the summary of findings from this field study, RJHS has developed strong support for the practices identified in the NCEA Best Practice Framework of five central themes mentioned above. RJHS is a high performing school that fits the framework articulated by Luce and Thompson (2005).

\section{Research Question 2}

To what extent is Relational Trust developed in the high performing school?

Fifty-six percent of the RJHS staff participated in a Relational Trust Survey adopted from the educational research of Anthony Bryk and Barbara Schneider (2002). On the Teacher-Principal Trust Survey, RJHS teacher respondents reported $100 \%$ trust in the principal's ability to do the work. Likewise, teachers reported $100 \%$ respect for the principal as an educator. This entire survey was overwhelmingly positive concerning relational trust with the principal.

On the Teacher-Teacher Role Relations Survey, RJHS teachers reported a great deal of respect among their colleagues and for those who take a leadership role in school improvement efforts. Seventy-one percent of the teachers expressed a strong "can do" 
attitude, $50 \%$ reported that teachers really care about each other somewhat, and $42 \%$ reported "caring to a great extent."

On the Teacher-Parent Role Relations Survey, RJHS teachers reported minimal levels of confidence in parents to do their best to help their children learn and to support teachers. Teachers reported a great deal of concern among colleagues for the local community and perceived teachers and parents as partners in educating children. Teachers reported a moderate level of conflict exists between parents and teachers but most teachers indicated that they try to understand parents' problems and concerns.

According to Bryk and Schneider (2002), "The growth of relational trust in a school community - fuels these multiple strands in the school change process and thereby contributes to improved student learning. Clearly, relational trust matters as a resource of school improvement" (p. 121). Based on the summary of findings in this high performing school used in this study, and in accordance with the concepts of relational trust researched by Bryk and Schneider (2002), relational trust undergirds all social interactions in this high performing school.

\section{Research Question 3}

To what extent is instructional program coherence developed in the high performing school?

According to rubric results, RJHS teachers reported that all teachers within a grade connect some of their curriculum to the specified learning goals. All RJHS teachers within a grade use some common instructional strategies. Likewise, all RJHS teachers within a grade use some common assessment strategies. All RJHS teachers coordinate all curriculum and assessments across the grades. Almost all support programs are linked to 
the curriculum. Professional development for RJHS staff extensively supports the implementation of common curriculum, instructional strategies, and assessments and many are sustained over time. At RJHS a great deal of school improvement planning and assessment addresses the school's progress in providing a common, coordinated, and sustained school program. RJHS's curriculum and assessment are stable over time and teachers have sustained opportunities to teach it well. Likewise, many teaching assignments and most key program leaders or leadership positions are stable over time and rarely change.

To quote Newmann, Smith, Allensworth, and Bryk (2001), "To improve student achievement, school staffs and the external organizations that work with them should aim to strengthen instructional program coherence" (p. 316). Based on the summary of findings in the high performing school used in this study, and in accordance with instructional program coherence literature, this practice was found to be highly developed and constantly evaluated in this high performing school.

\section{Research Question 4}

What is the influence of the principal's leadership style on the staff and school climate?

Leadership at RJHS is anything but top down or authoritative; rather, leadership is open, shared, and viewed as a partnership by the staff. Teachers are included in most curricular and instructional decisions and, therefore, are very supportive of the framework and willing to go the extra mile to ensure the school's success. The principal believes very strongly in the concept of teamwork and works to create many opportunities for the teachers to work together. The principal prefers a team approach to staff selection, so a team of teachers is formed based on grade level and subject area for the 
hiring process. One teacher commented that the principal is always straightforward with people. Teachers appreciate the principal's open door policy and most feel free to go to her with a problem. Through open dialogue at faculty meetings, teacher team meetings, and the principal's open door policy, teachers at RJHS have gained a strong voice in all decision-making. One teacher commented, "The principal presents ideas to the teachers then we have a forum discussion and vote." As observed at RJHS, the principal sets clear expectations for the staff and holds them accountable through monitoring and progress meetings. The principal is accessible to teachers and students and is visible in the building and school grounds. The principal knows many of the students and addresses them by name when she encounters them at school. The principal indicated that she believes in supporting teachers in the classrooms so she spends a lot of time in classrooms, especially with new teachers. On the Teacher-Principal Role Relation Survey, $100 \%$ of the teachers who participated reported that they really respect the principal as an educator and trust the principal at her work.

In the words of Fullan (2001), "I know of no improving school that doesn't have a principal who is good at leading improvement. Almost every single study of school effectiveness has shown both primary and secondary leadership to be a key factor" (p. 141). Based on the summary of findings of the high performing school used in this study, and in accordance with the practices identified as important leadership qualities, this high performing school's success is greatly impacted by its outstanding principal.

\section{Research Question 5}

How do the five themes of the Illinois Best Practice Framework, instructional program coherence, and relational trust contribute in creating a professional learning community? 
As discussed throughout this study, the NCEA Best Practice Framework encompasses the curriculum and academic goals, staff selection, leadership, and capacity building, instructional programs, practices, and arrangements, monitoring, compilation, analysis, use of data, recognition, intervention, and adjustment practices at the district, school and classrooms levels. These themes address every important detail of a school's academic operation and purpose for existing.

The professional learning community is a popular concept for organizing and operating schools that move away from the more bureaucratic concepts and principles of the factory model that often under utilized the expertise and ideas of teachers and other staff. According to DuFour and Eaker (1998), the professional learning community is an idea whose time has come. DuFour and Eaker (1998) state:

Researchers both inside and outside of education have arrived at the same conclusions regarding a new model that offers the best hope stimulating significant improvement in the ability of schools to achieve their objectives. This model requires schools to function as professional learning communities characterized by a shared mission, vision, and values; collective inquiry; collaborative teams; and orientation toward action and a willingness to experiment; commitment to continuous improvement; and a focus on results. (p. 45)

The five themes encompassed in the NCEA Best Practice Framework, instructional program coherence, and relational trust are all embedded in the practices of a PLC.

The concept of instructional program coherence is defined as "... a set of interrelated programs for students and staff that are guided by a common framework for curriculum, instruction, assessment, and learning climate and that are pursued over a sustained period" (Newmann, Smith, Allensworth, \& Bryk, 2001, p. 297). This concept calls for established common practices within a school, which eliminates teachers working in isolating conditions and focuses the entire school community around a 
common curricular framework. The characteristics of instructional program coherence are also embedded in the practices of a PLC.

The concept of relational trust addresses the social interactive dynamics among all the people that make up a school community. Relational trust is most important because it involves the willingness of people to respect each other, trust that colleagues to do their jobs well, share common values, and work toward the success of the entire school. To quote Bryk and Schneider (2002):

The presence of relational trust among a faculty allows it to coalesce as a professional community where teachers can undertake genuine collective work together. This is important because critical aspects of instructional improvement (such as curriculum alignment across classrooms and maintaining internal accountability among professional staff to ensure that all students learn) require joint problem-solving among teachers and therefore make significant demands on the social resources of a school's faculty. (pp. 116-117)

As stated by the founding researchers, relational trust enables a faculty to operate as a professional learning community. In fact, relational trust establishes the foundation for all other crucial school works to follow. The important characteristics of relational trust undergird the practices of a PLC. In fact, the five themes of the NCEA Best Framework, instructional program coherence, relational trust and PLC are all interconnected and interdependent. These interconnections are depicted in Table 4. 
Table 4

Interconnections: NCEA Themes, Professional Learning Community (PLC), Instruction Program Coherence (IPC), and Relational Trust (RT)

\begin{tabular}{|c|c|c|c|}
\hline $\begin{array}{l}\text { NCEA } \\
\text { Themes }\end{array}$ & PLC & IPC & RT \\
\hline $\begin{array}{l}\text { Curriculum \& } \\
\text { Academic Goals }\end{array}$ & $\begin{array}{l}\text { Shared Mission, } \\
\text { Vision \& Values }\end{array}$ & $\begin{array}{l}\text { Common Curricular } \\
\text { Framework }\end{array}$ & Shared Values \\
\hline $\begin{array}{l}\text { Staff Selection } \\
\text { Leadership \& } \\
\text { Capacity Building }\end{array}$ & $\begin{array}{l}\text { Collaborative Teams, } \\
\text { Collective Inquiry }\end{array}$ & $\begin{array}{l}\text { Professional Development } \\
\text { Staff Working Conditions } \\
\text { Criteria for Recruiting }\end{array}$ & $\begin{array}{l}\text { Social Capital } \\
\text { \& Networking, } \\
\text { Integrity, } \\
\text { Regard for } \\
\text { Others }\end{array}$ \\
\hline $\begin{array}{l}\text { Instructional } \\
\text { Programs, \& } \\
\text { Arrangements }\end{array}$ & $\begin{array}{l}\text { Action Research \& } \\
\text { Experimentation }\end{array}$ & $\begin{array}{l}\text { Common Instructional } \\
\text { Programs, Practices, \& } \\
\text { Assessments, \& Sustained } \\
\text { Arrangements }\end{array}$ & $\begin{array}{l}\text { Competence } \\
\text { \& Internal } \\
\text { Accountability } \\
\text { Role } \\
\text { Obligations }\end{array}$ \\
\hline $\begin{array}{l}\text { Monitoring: } \\
\text { Compilation, } \\
\text { Analysis, \& } \\
\text { Use of Data }\end{array}$ & $\begin{array}{l}\text { Continuous } \\
\text { Improvements }\end{array}$ & $\begin{array}{l}\text { Analysis of Student Data } \\
\text { \& Data Driven Decisions }\end{array}$ & $\begin{array}{l}\text { Collaboration, } \\
\text { Teaming, and } \\
\text { Faculty Sharing }\end{array}$ \\
\hline $\begin{array}{l}\text { Recognition, } \\
\text { Intervention \& } \\
\text { Adjustment }\end{array}$ & $\begin{array}{l}\text { Focus on Results, } \\
\text { Collegial Support } \\
\text { Accountability }\end{array}$ & $\begin{array}{l}\text { Key Student Support } \\
\text { Programs }\end{array}$ & $\begin{array}{l}\text { Good Student \& } \\
\text { Parent Rapport, } \\
\text { Parental Support }\end{array}$ \\
\hline
\end{tabular}

\section{Implications and Recommendations for Policy and Practice}

\section{Implications}

This study has revealed that school improvement is a multifaceted endeavor that requires the commitment of the entire school community. School improvement also requires the collective efforts of the entire school community working simultaneously in multiple areas to strengthen weaknesses that lead to school failures. As evidenced by the findings in this study and supportive scholarly research literature, schools seeking to 
improve must strengthen multiple areas such as those identified in the NCEA Best Practice Framework (curriculum and academic goals; staff selection, leadership and capacity building; instructional programs, practices, and arrangements; monitoring, compilation, analysis, and use of data; recognition, intervention and adjustment). Also, schools must develop relational trust, maintain instructional program coherence, and establish a professional learning community to realize improvements that will result in increased student achievement. These developments can only happen under the guidance and support of a strong principal.

The NCEA Best Practice Framework has been touted as the template of best practices found in high performing schools across the United States. According to Luce and Thompson (2005), the Best Practice Framework is highly replicable and has become widely adopted by schools looking to improve.

The Best Practice Framework thus provides a structure for communicating what high performing school systems are doing to get results. This usable organizational tool supplies access not only to a listing of best practices, but also to a full set of tools that facilitate enactment of the practices. (p. 70)

In the past two decades, the five areas cited in the framework have become common knowledge to many educators and cover most of the strategic areas that school reformers are continuously striving to manage. Schools looking to improve would do well to consider this NCEA Best Practice Framework.

Next, schools seeking to improve must also address the relational trust factor. Relational trust or the lack thereof has a powerful impact on all of the important work that people in schools must do. Relational trust views social interactions in schools as a set of role relations such as principal-teacher, teacher-teacher, and teacher-parent. Within each role are certain obligations one is expected to perform and expectations about the 
obligations of others. All roles are interdependent and require social interactions between them to carry out the important work in schools. According to Bryk and Schneider (2002):

A strong base of relational trust lubricates much of a school's day-to-day functioning and is a critical resource as local leaders embark on ambitious education reforms. These findings have important implications for the extensive efforts, now ongoing nationwide, to enhance student learning. (p. 133)

Likewise, schools seeking to improve must also address the instructional program coherence within the school. As stated by Newmann, Smith, Allensworth, and Bryk (2001), "The most straightforward implication of these findings is that leaders in schools, in school improvement organizations, and in district, state, and federal agencies should give more deliberate attention to strengthening instructional program coherence within schools" (p. 315). Strengthening instructional program coherence in a school is the work of entire school community and requires simultaneous efforts from the bottom up and from the top down (Newmann, Smith, Allensworth, \& Bryk, 2001).

Last but of utmost importance, schools seeking to improve must embrace a new model for schooling that offers the best strategies for school improvement. This new model is a professional learning community (PLC) created within schools whereby administrators, and teachers are regarded as learners and leaders in the school. "The PLC concept operates from the premise that leadership should be widely dispersed throughout a school, and thus developing the leadership potential of all staff members is imperative" (DuFour, Eaker, \& DuFour, 2005, p. 23). The salient characteristics of a PLC are creation of a shared mission and vision for the school, collaborative teamwork and collective inquiry, action research and experimentation, a quest for continuous improvements, and a focus on results. According to DuFour, Eaker, and DuFour (2005), 
A broad, even remarkable concurrence among educational researchers and organizational theorists who have concluded that developing the capacity of educators to function as members of professional learning communities is the best-known means by which we might achieve truly historic, wide-scale improvements in teaching and learning. (p. 7)

This investigation of a high performing school follows a path frequently traveled by numerous researchers in the past quarter century. The search for the secret of successful schools seems to lead to the principal's office. None of the laudable precepts identified by best practices, relational trust, and instructional program coherence would have any chance of flourishing at RJHS without a highly competent principal who embodies respect for the school's students, teachers, and parents.

Principals make a difference. They not only set the tone in the school but also play many roles that often seem contradictory. For example, they serve as the lead mentor for new and veteran teachers as professional friends, yet they also assume top management roles with the authority to supervise and sanction those who fail to meet high professional standards. The duty to be both friend and critic is not an easy social space to occupy. Yet successful principals in schools like RJHS work in this zone of tension and adaptive adjustment with finely honed interpersonal skills. Leadership style is an important factor that greatly impacts the success of a school.

\section{Considerations for Further Research}

During the research for this study, many successful practices were identified.

Field studies continue to identify these core concepts, yet schools are unable to implement and sustain these practices. More research is needed to identify what factors contribute to school failure and the inability of schools to implement change. Additional 
research is warranted to identify the barriers to becoming an effective school and how these barriers might be eliminated.

The school district in this study played an important role in providing meaningful professional development for teachers, and it facilitated teacher collaboration between schools in the district. This school district also facilitated collaboration among principals within the district. We need to know more about how a school district office can help set the stage for sustained improvements in schools and how a school district can support school leadership that cultivates teacher-to-principal and teacher-to-teacher relational trust.

As a result of the study, it was revealed that the staff worked beyond their contractual hours without additional compensation on a daily basis in order to fulfill school goals. Teacher contracts are too restrictive to fulfill the time elements required for high performance. We need to know how schools can solve the problem of contractual time limitations.

\section{Recommendations for Policy and Practice}

Many urban schools struggle with the culture of the streets invading schools and impeding education. As a result of the study, a system was identified that controlled this potential problem thus keeping street culture out of the school. This school developed a strategic system of rewards and sanctions that motivated students to enthusiastically comply. The system involved student uniforms, tracking of disciplinary infractions, and rewards such as fieldtrips, pizza luncheons, public praise and recognition, school dances, after-school basketball court time, computer time, etc. A weekly report that detailed infractions was made during staff meetings. This system accented positive behavior with 
rewards. Sanctions for noncompliance were in the form of elimination from the planned extracurricular activities. The entire staff helped develop this system and it was highly supported by all. The dean of students was responsible for monitoring, tracking infractions, and making weekly reports.

This highly effective disciplinary system is easily replicable, practical, and relatively inexpensive to implement. This system can be tailored to the specific characteristics of other schools. In fact, others schools could benefit greatly from this doable system.

\section{Conclusion}

The Effective Schools movement put a face on school failure and the disparity in educating poor students and minorities more than 40 years ago. Today, educators are still struggling to improve schools amidst public ridicule combined with federal and state policy changes that continue to call for new reforms.

In the midst of this storm, RJHS is an effective school that is successfully educating poor and minority students. This school embodies a strong sense of shared values, in its history, culture, and success. There is an overwhelming quest for continuous improvement that is shared by the staff. When a program is not working, the entire staff comes together to find a solution. Operations at RJHS are planned, deliberate, and well executed with all the staff focused on the success of students. This unified focus on success is the "Ethos of Excellence" embodied by the staff that pervades all operations at RJHS.

RJHS's success should not be viewed as unique or unattainable. In fact, one should speculate that if this school can succeed in educating poor and minority students, 
then why not others. Ronald Edmonds (1979) argued that, "Repudiation of the social science notion that family background is the principal cause of pupil acquisition of basic school skills is probably prerequisite to successful reform of public schooling for the children of the poor" (p. 23). Reflection on Edmonds' statement raises an important question: how many educators truly believe that all children can learn or how many have let negative beliefs influence their motivation to teach all children well? 


\section{REFERENCES}

Baker, P. J. (1991, April). Metaphors of mindful engagement and a vision of better schools. Educational Leadership, 30, 32-35.

Baker, P. J. (1996, April). Building learning communities through guided participation. Primary Voices $K-6$.

Baker, P. J. (1999). The leadership challenge: Caught in the middle of the school reform era. Planning and Changing, 30, 154-174.

Becker, M. (1992). An effective schools primer. Arlington, VA: American Association of School Administrators.

Bryant, M. T. (2004). The portable dissertation advisor. Thousands Oaks, CA: Corwin Press.

Bryk, A., Camburn, E., \& Louis, K. (1999). Professional community in Chicago elementary schools: Facilitating factors and organizational consequences. Educational Administration Quarterly, 35, 751-781.

Bryk, A. S., \& Schneider, B. (2002). Trust in schools: A core resource for improvement. New York: Russell Sage Foundation.

Bryk, A. S., Sebring, P. B., Kerbow, D., Rollow, S., \& Easton, J. Q. (1998). Charting Chicago school reform: Democratic localism as a lever for change. Boulder, $\mathrm{CO}$ : Westview Press.

Cooter, R. (2003). Teacher "Capacity-building" helps urban children succeed in reading. International Reading Association, 57, 198-205.

Curry, L., Pacha, J., \& Baker, P. (2007). The Illinois best practice school study: 20032006. Normal, IL: Center for the Study of Education Policy at Illinois State University.

Curry, L., Pacha, J., \& Baker, P. (2007). Coming full circle: An ethos of excellence emerges from decades of school effectiveness research. Normal, IL: Illinois State University.

Creswell, J. (2003). Research design. Thousand Oaks, CA: Sage Publications. 
Darling-Hammond, L., \& Sykes, G., (1999). Teaching as the learning profession: Handbook of policy and practice. San Francisco, CA: Jossey-Bass.

Darling-Hammond, L. (2001). The right to learn: A blueprint for creating schools that work. San Francisco, CA: Jossey-Bass.

DuFour, R., \& Eaker, R., (1998). Professional learning communities at work: Best practices for enhancing student achievement. Bloomington, IN: National Educational Service.

DuFour, R. (2002, May). The learning-centered principal. Educational Leadership, 1215.

DuFour, R., \& Eaker, R. (2005). On common ground: The power of professional learning communities. Bloomington, IN: Solution Tree.

Elmore, R., \& Burney, D. (1999). Building a new structure for school leadership. Washington, DC: The Albert Shanker Institute.

Elmore, R. (2002). Bridging the gap between standards and achievement: The imperative for professional development in education. Washington, DC: The Albert Shanker Institute.

Fullan, M. (2001). The new meaning of educational change. New York: Teachers College Press.

Fullan, M. (2002). The change leader. Educational Leadership, 59, 16-20.

Glesne, C. (1999). Becoming qualitative researchers. New: Longman.

Joyce, B., \& Calhoun, E. (1995, April). School renewal: An inquiry, not a formula. Educational Leadership.

Joyce, B., Murphy, C., Showers, B., \& Murphy, J. (1989, November). School renewal as cultural change. Educational Leadership.

Kruse, S., \& Louis, K. (1997, August). Teacher teaming in middle schools: Dilemmas for a schoolwide community. Educational Administration Quarterly, 33, 261-289.

LeCompte, M. D., \& Preissle, J. (1993). Ethnography and qualitative design in educational research. San Diego, CA: Academic Press.

Leithwood, K., \& Louis, K., (1998). Organizational learning in schools. Exton, PA: Swets \& Zeitlinger Publishers.

Lezotte, L. W. (1991). Correlates of effective schools: The first and second generation. Okemos, MI: Effective Schools Products, Ltd. 
Linn, R., Baker, E., \& Betebenner, D. (2002). Accountability systems: Implications of requirements of the No Child Behind Act of 2001. Educational Researcher, 31, 316.

Little, J. W. (1982). Norms of collegiality and experimentation: Workplace conditions of school success. American Educational Research Journal, 19, 325-340.

Luce, T., \& Thompson, L. (2005). Do what works: How proven practices can improve America's public schools. Texas: Ascent Educational Press.

Mace-Matluck, B. (1987). The effective schools movement: Its history and context. Austin, TX: Southwest Educational Development Lab.

Marks, H., \& Louis, K. (1999, December). Teacher empowerment and the capacity for organizational learning. Educational Administration Quarterly, 35, supplemental, 707-750.

Marzano, R. J. (2003). What works in schools. Alexandria, VA: Association for Supervision and Curriculum Development.

Merriam, S. (1988). Case study research in education. San Francisco: Jossey-Bass.

National Commission on Excellence in Education. (1983). A nation at risk. Washington, DC: U.S. Government Printing Office.

Newmann, F., King, M., \& Rigdon, M. (1997). Accountability and school performance: Implications from restructuring schools. Harvard Educational Review, 67, 41-69.

Newmann, F., King, M., \& Youngs, P. (2000, August). Professional development that addresses school capacity: Lessons from urban elementary schools. American Journal of Education, 108, 259-299.

Newmann, F., Smith, B., Allensworth, E., \& Bryk, A. (2001). Instructional program coherence: What it is and why it should guide school improvement policy. Educational Evaluation and Policy Analysis, 23(4), 297-321.

Senge, P. (1990). The leader's new work: Building learning organization. New York: MIT Sloan School of Management.

Stake, R. (1995). The art of case study research. Thousand Oaks, CA: Sage Publications.

Schein, E. H. (1997). Organizational culture and leadership. San Francisco: Jossey-Bass.

Sergiovanni, T. J. (2000). The lifeworld of leadership. San Francisco: Jossey-Bass. 
Stoll, L., \& Fink, D. (1996). Changing our schools: Linking school effectiveness and school improvement. Buckingham, PA: Open University Press.

Wasley, P., (2000). Small schools: Great strides: A study of new small schools in Chicago. Chicago, IL: Bank Street College of Education. 
APPENDIX A

NCEA INTERVIEW PROTOCOL FOR TEACHERS AND ADMINISTRATORS 
Interview Questions for Teachers and Administrators

National Center For Educational Accountability

\section{Overview: Supporting Factors}

1. To what do you attribute your school's level of success?

2. What are the key priorities for your school?

3. Over the past 3 years, what school-wide reform has had the greatest effect on improving student achievement?

4. What are the primary challenges facing your school?

5. Describe your overall school climate.

6. Please describe any formal organizational structures designed to promote communication across the district.

7. Describe the role of your teachers' union/association in your school.

8. Describe the role of parents in promoting student academic achievement in your school.

\section{Theme 1: Curriculum and Academic Goals}

1. How do you know exactly what is to be learned in your grade and subject?

2. What curricular materials are supplied by your district?

3. How did you learn about the district curriculum?

4. Describe your involvement in curriculum development.

5. Describe your involvement in curriculum revision.

6. What percentage of students enter your classroom with the necessary skills to begin the work of your grade/subject?

7. How does the school develop academic goals?

8. Is there any additional information relative to curriculum and academic goals that you would like to share? 


\section{Theme 2: State Selection, Leadership, and Capacity Building}

1. Describe the process used to select teachers in your district.

2. What support activities or programs are in place for new teachers at your school?

3. Describe the professional development provided to teachers by the district this year.

4. What processes are in place to retain effective teachers?

5. How does this school provide instructional support to teachers?

6. Describe how you collaborate with your colleagues, if at all.

7. How often have you visited other classrooms this year?

8. Is there any additional information about teacher selection or development that you would like to share?

9. How are teachers involved in the principal selection process?

10. Describe any programs or processes used to develop internal candidates for the principalship.

11. Is there any additional information about principal selection or development that you would like to share?

\section{Theme 3: Instruction Program, Practices, and Arrangements}

1. How are the instructional materials that you use selected?

2. What programs, if any, have been mandated by the district?

3. How is the effectiveness of selected programs evaluated?

4. Is there any additional information about instructional programs that you would like to share?

5. How would you describe high-quality classroom instruction?

6. How has the state accountability system impacted your instructional practices, if at all?

7. Describe any instructional practices that are mandated or strongly encouraged by your district or school? 
8. Is there any additional information about instructional practices that you would like to share?

9. What are the district policies for how much instructional time is spent in core content areas (math, reading, writing, science, and social studies)?

10. How does the school schedule impact classroom instruction?

11. Please describe how the following student groups are served in this district.

12. Is there any additional information about instructional arrangements that you would like to share?

\section{Theme 4: Monitoring: Gathering, Analysis, and Use of Data}

1. How does your school monitor its goals?

2. How would you describe the quality of your state assessment?

3. How do you monitor your students' progress?

4. What other benchmarks or assessments are administered by the district, other than the state assessments?

5. How are these assessments developed?

6. Describe the district's student data monitoring system.

7. How do you use the student data monitoring system?

8. Describe your teacher evaluation process.

9. Describe any additional methods used to monitor classroom instruction.

10. Is there any additional information about monitoring system, school, educator, or student performance that you would like to share?

\section{Theme 5: Recognition, Intervention, and Adjustments}

1. Describe one or two school recognition programs or activities tied to student achievement.

2. What types of interventions are in place to support struggling teachers?

3. What specific interventions are in place to support students? 
4. Describe the district promotion policy.

5. Describe the process for making adjustments to the curriculum.

6. Describe how you make adjustments to your classroom instruction based on your review of student data.

7. Is there any additional information about recognition, interventions, or adjustments that you would like to share? 
APPENDIX B

NCEA/ILLINOIS BEST PRACTICE FRAMEWORK 
nlinais Rest Practice Skudy Framework

\begin{tabular}{|c|c|c|c|c|}
\hline & Orgaruine Khemes & Distiet Lerel & Sehad Livel & Classtoam teval \\
\hline $\begin{array}{l}\text { NCE } \\
\text { thoms } \\
\text { I }\end{array}$ & 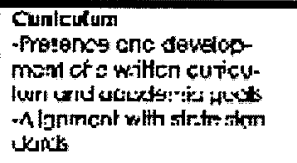 & 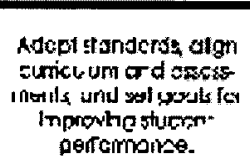 & 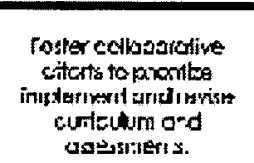 & 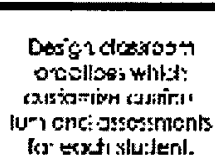 \\
\hline $\begin{array}{c}\text { NCER } \\
\text { Ineme } \\
2\end{array}$ & 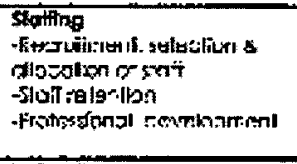 & 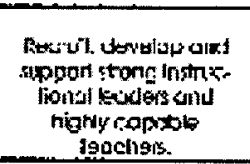 & 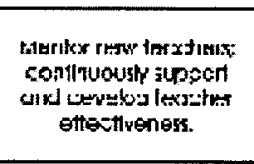 & 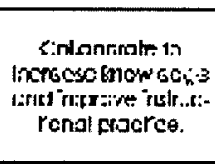 \\
\hline $\begin{array}{c}\text { MCEA } \\
\text { Theme } \\
3\end{array}$ & 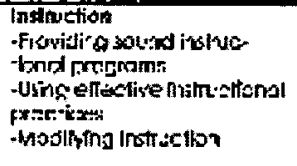 & 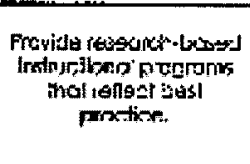 & 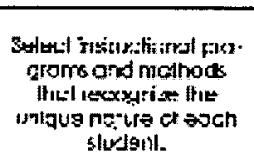 & 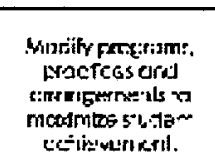 \\
\hline $\begin{array}{c}\text { NCEA } \\
\text { Theme } \\
4\end{array}$ & 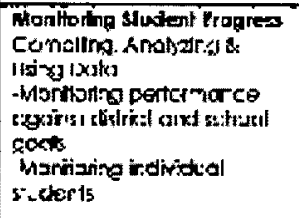 & 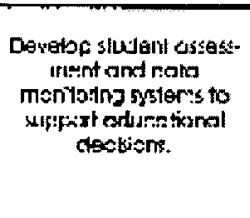 & 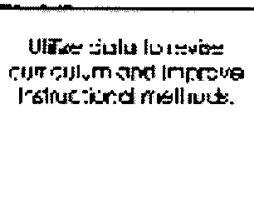 & 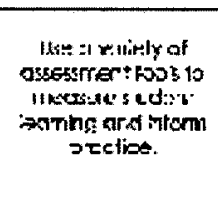 \\
\hline $\begin{array}{c}\text { MEEA } \\
\text { Theme } \\
5\end{array}$ & 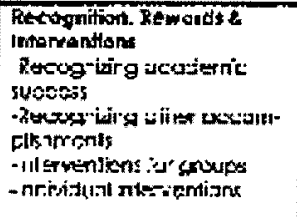 & 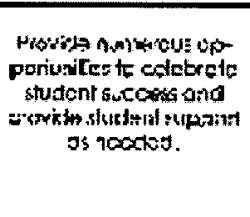 & 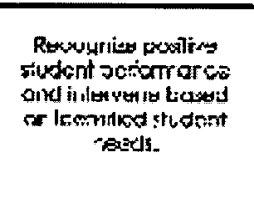 & 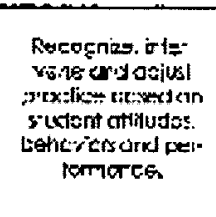 \\
\hline 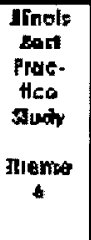 & 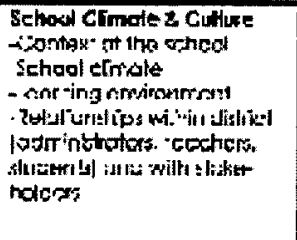 & 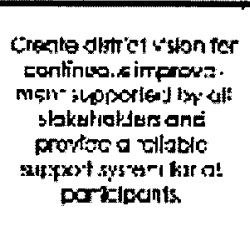 & 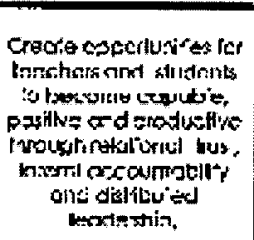 & 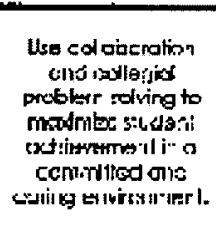 \\
\hline
\end{tabular}


APPENDIX C

LETTER OF EXPLANATION AND CONSENT TO PARTICIPATE 
February 2006

\section{Dear Colleague:}

As a doctoral candidate at Illinois State University, I am in the process of working on my dissertation. The purpose of this study is to examine an exemplary urban school serving low-income students in an attempt to identify educational practices that contributes to successful school performance. This study will examine factors that contribute to a professional learning community that cultivates relational trust and instructional program coherence. Upon completion, the good new of your school's successful practices will be shared with educators across the nation via the Just For Kids Website.

As a part of my dissertational research, I will be conducting educator interviews, school and classroom observations, and collecting supporting documents. I will request the use of a recorder to avoid the limitations of trying to write every thing. Your participation in this dissertation study is strictly voluntary and anonymous. Participation may be discontinued at any time during the study without penalty. There is no penalty for nonparticipation.

All information gathered is to be used solely for the purpose of my dissertation research. Any information presented in written and or oral presentations will be utilized within and overall school context and will never reveal individual responses.

If you have any questions or concerns, please feel free to contact me at $\square$ or you may contact my principal investigator, Dr. Paul J. Baker at (309) 438-3873 or the Research Ethics \& Compliance Office at (309) 438-8451.

I would really appreciate your participation.

Sincerely,

Karen Gyenfie 


\section{Consent to Participate}

$\mathrm{I}$, , hereby give my consent to participate in Karen

Gyenfie's dissertation research on the study of a high performing urban school's educational practices. I understand that I will be interviewed about my perceptions and the school's educational practices. The interview will take place during the school day at my convenience and that observations in my classroom may take place as well. I understand that all names of participants and the school will be changed to protect the privacy of all participants. I understand that I may discontinue my participation in the study at any time without penalty. 
APPENDIX D

RELATIONAL TRUST SURVEY PROTOCOL 


\section{Relational Trust Survey}

(Rasch Rating Scale)

Bryk, A., \& Schneider, B. (2002)

To what extent do you agree or disagree with each of the following statements? strongly disagree (1); disagree (2); $\quad$ agree (3); $\quad$ strongly agree (4)

\section{Teacher-Principal Trust Items}

1. It's OK in this school to discuss feelings, worries, and frustrations with the principal.

2. The principal looks out for the personal welfare of the faculty members.

3. I trust the principal at his or her work.

4. The principal at this school is an effective manager who makes the school run smoothly.

5. The principal places the needs of children ahead of her personal and political interests.

6. The principal has confidence in the expertise of the teachers.

7. The principal takes a personal interest in the professional development of teachers.

8. I really respect my principal as an educator.

9. To what extent do you feel respected by your principal.

\section{Teacher-Teacher Trust Items}

1. Teachers in this school really care about each other?

2. Teachers in this school trust each other.

3. It's OK in this school to discus feelings, worries, and frustrations with other teachers.

4. Teachers respect other teachers who take the lead in school improvements efforts.

5. Teachers at this school respect those colleagues who are expert at their craft.

6. To what extent do you feel respected by other teachers? 


\section{Teacher-Parent Trust Items}

1. How many of your students' parents do their best to help their children learn?

2. How many teachers at this school feel good about parents' support for their work?

3. How many teachers at this school really care about this local community?

4. How many of your students' parents support your teaching effort?

5. Teachers and parents think of each other as partners in educating children?

6. There is conflict between parents and teachers at this school.

7. Parents are invited to visit classrooms to observe the instructional program.

8. Teachers really try to understand parents' problems and concerns. 